\title{
Optimal monetary policy with international trade in intermediate inputs
}

\author{
Liutang Gong a , Chan Wang a,*, Heng-fu Zou b,c,d \\ a Guanghua School of Management and LMEQF, Peking University, Beijing 100871, China \\ ${ }^{\mathrm{b}}$ China Economics and Management Academy, Central University of Finance and Economics, Beijing 100081, \\ China \\ ${ }^{\mathrm{c}}$ Institute for Advanced Study, Wuhan University, Wuhan 430072, China \\ d Institute for Advanced Study, Shenzhen University, Shenzhen 518060, China
}

\section{A R T I C L E I N F O}

\section{Article history:}

Available online 7 April 2016

\section{JEL classification:}

E5

F3

F4

Keywords:

Vertical production and trade

Optimal monetary policy

Inflation targeting

Welfare

\begin{abstract}
A B S T R A C T
This paper examines optimal monetary policy in a two-country New Keynesian model with international trade in intermediate inputs. We derive the loss function of a cooperative monetary policymaker and find that the optimal monetary policy must target intermediategoods price inflation rates, final-goods price inflation rates, finalgoods output gaps, and relative-price gaps. We use the welfare loss under the optimal monetary policy as a benchmark to evaluate the welfare implications of three Taylor-type monetary policy rules. A main finding is that the degree of price stickiness at the stage of intermediate-goods production is a key factor to determine which policy rule should be followed. Specifically, when the degree of price stickiness at the stage of intermediate-goods production is high, the policymaker should follow intermediate-goods PPI-based Taylor rule, whereas CPI-based Taylor rule should be followed when the degree of price stickiness at the stage of intermediate-goods production is intermediate or low.
\end{abstract}

(c) 2016 Elsevier Ltd. All rights reserved.

\section{Introduction}

The global economy is increasingly integrated by vertical production and trade, ${ }^{1}$ more and more countries are trading not only in final consumption goods but also a large quantity of intermediate

\footnotetext{
* Corresponding author. Tel.: +86 13681573387.

E-mail address: wangchanist@126.com (C. Wang).

1 Naturally, vertical production and trade involves international trade in intermediate inputs.
} 
inputs (Bridgman, 2012; Feenstra, 1998; Hummels et al., 1998, 2001; Johnson, 2014; Yi, 2003, 2010). ${ }^{2}$ A natural question arises: what can we say about the effect of international trade in intermediate inputs on the design of optimal monetary policy? The question is important both for policy practice and academic research. However, the research on the point is scant. ${ }^{3}$ In fact, in Clarida et al. (2002), a canonical article using the New Keynesian framework to analyze open-economy monetary policy, the authors believe that allowing trade in intermediate inputs is particularly interesting, as it introduces an additional effect of openness on marginal cost. ${ }^{4}$ Therefore, they recommend this topic to be further researched. In this paper, we fill the gap and examine the role of international trade in intermediate inputs in shaping optimal monetary policy in open economies theoretically. For the sake of practicality, we also examine what kind of rule is the best choice for monetary policymakers in the sense that the welfare attained by following the rule is the nearest approximation to that attained by following the optimal monetary policy.

Building on Clarida et al. (2002), Gali and Monacelli (2005), and Engel (2011), we introduce vertical production and trade into an open-economy monetary model with nominal rigidities to examine optimal monetary policy. ${ }^{5}$ In our model, there are two stages of production and trade. We take the home country as an example to illustrate vertical production and trade. At the stage of final-goods production, a continuum of firms use home and foreign intermediate goods to produce differentiated goods, which then are consumed by home and foreign households. At the stage of intermediategoods production, a continuum of firms use domestic labor to produce differentiated goods, which then are used as inputs by home and foreign final-goods producers. At each stage of production, the prices are set in a staggered fashion, as in Calvo (1983). Thus, there are two natural candidates for PPI: final-goods PPI and intermediate-goods PPI. As usual, the price index facing households is CPI. As will be evident, the distinction between various price indexes is important to analyze the macroeconomic dynamics and the relative welfare ranking of three Taylor-type rules. In Huang and Liu (2001, 2005, 2006, 2007), the degree of price stickiness is identical at both stages of production. However, substantial empirical studies find that the degree of price stickiness at the different stages of production is different, ${ }^{6}$ thus we depart from Huang and Liu $(2001,2005,2006,2007)$ and assume different degrees of price stickiness at both stages of production. ${ }^{7}$ In addition, different from Devereux and Engel (2003) and Engel (2011), we set aside the empirically relevant case of local-currency pricing (LCP) and assume that firms at both stages set prices in their own currency (producer-currency pricing or PCP).

As predicted by Clarida et al. (2002), the introduction of international trade in intermediate inputs indeed results in an additional effect of openness on marginal cost. In Clarida et al. (2002) and Engel (2011), the real marginal cost depends on home and foreign output gaps. In our model, the real marginal costs at both stages of production are determined not only by home and foreign output gaps but also by home and foreign relative-price gaps. In addition, labor demands in both countries are

\footnotetext{
2 In the field of international trade, the literature on vertical production and trade is voluminous; we just mentioned some prominent examples. See Huang and Liu (2007) for many relevant references.

3 As far as we know, Obstfeld (2001), Devereux and Engel (2007), Shi and Xu (2007), and Wang and Zou (2015) are several exceptions. However, these models assume that prices are set one period in advance. As a comparison, we consider Calvotype staggered price-setting, which allows for richer dynamics. In addition, staggered price setting leads to relative price distortions and implies a cost from inflation, which is absent from models in which all prices are set one period in advance.

4 As defined in Monacelli (2013), it is production openness.

5 Within the limit of our knowledge, Huang and Liu (2001) first introduce vertical production chains in a closed economy with nominal rigidities to discuss aggregate dynamics following a monetary shock. Thereafter, in Huang and Liu (2005), they examine optimal monetary policy in a closed economy with two-stage production structure, and find that a simple monetary policy rule which requires the interest rate to respond to CPI inflation and PPI inflation will result in a welfare level close to the optimum; in Huang and Liu (2006), they consider vertical production and trade in an open economy to study international transmissions and welfare implications of monetary shocks; in Huang and Liu (2007), they introduce vertical production and trade in an open economy to study international business cycle.

${ }^{6}$ Murphy et al. (1989) and Clark (1999) find that for the aggregate US PPI, intermediate goods, raw materials in particular, are much more volatile than final goods. Based on the data at the micro level, Bils and Klenow (2004) estimate that the prices of raw goods are 3-4 times more volatile than processed goods. Using the data underlying the US CPI and PPI, Nakamura and Steinsson (2008) estimate that final-goods prices are stickier than intermediate goods.

7 On this point, we follow Devereux and Engel (2007). But, in their model, prices are set one period in advance.
} 
affected not only by the same factors as in Clarida et al. (2002) and Engel (2011) but also by intermediategoods terms of trade, home and foreign productivity shocks at the stage of final-goods production. In this sense, after vertical production and trade is introduced, both home and foreign productivity shocks at the stage of final-goods production act as world shocks.

In general, when a cost-push shock is introduced into an otherwise standard closed-economy New Keynesian model, the central bank will face a trade-off between closing the output gap and stabilizing the inflation (Gali, 2008), i.e. the "divine coincidence" (Blanchard and Gali, 2007) breaks down. In addition, when the model is extended to consider multiple nominal rigidities (Erceg et al., 2000) or multiple sectors (Huang and Liu, 2005), the "divine coincidence" also breaks down. In openeconomy New Keynesian monetary models, such as Clarida et al. (2002), Gali and Monacelli (2005) and Engel (2011), the "divine coincidence" also holds when there are no cost-push shocks. However, in our model, it breaks down even if there are no cost-push shocks. Thus, our finding implies that the conclusion in open economies is similar to its closed-economy counterpart. It is noteworthy that, in Huang and Liu (2005), when labor is not an input factor in final-goods producers' production function or two sectors are affected by identical shocks, the flexible-price equilibrium allocation can be achieved, but the same conclusion does not hold in our model.

Following the literature, we derive the welfare loss function of a cooperative monetary policymaker and find that the welfare loss function depends on the following variables: home and foreign finalgoods output gaps, home and foreign final-goods inflation rates, home and foreign intermediategoods inflation rates, and home and foreign relative-price gaps. The allocative function played by home and foreign relative-price gaps explains the reason for their appearance in the welfare loss function.

With the welfare loss function in hand, we can derive the optimal monetary policy under commitment and use the welfare loss under the optimal monetary policy as a benchmark to evaluate the welfare implications of three Taylor-type monetary policy rules. All of them require the nominal interest rate to respond systematically to final-goods output gap and some measures of inflation. The first is the conventional Taylor rule and has the nominal interest rate to target the CPI inflation, thus it is called the CPI-based Taylor rule (CPIT). The second has the nominal interest rate to target the finalgoods PPI inflation and is referred to as the final-goods PPI-based Taylor rule (F-GPPIT). Similarly, the last one has the nominal interest rate to target the intermediate-goods PPI inflation and is named as the intermediate-goods PPI-based Taylor rule (I-GPPI).

For long, there is a general consensus among academic researchers and policy makers that a central bank should close the output gap and stabilize the inflation. The inflation is uniformly viewed as CPI inflation. Is this view correct when the PPI inflation is different from the CPI inflation in that it is more volatile and less persistent (Clark, 1999)? In our model with international trade in intermediate inputs, taking the welfare level under the optimal monetary policy as a benchmark, we find that the conventional CPI-based Taylor rule is not always a good choice for the policymaker, following it will result in a higher welfare loss in some cases. The degree of price stickiness at the stage of intermediate-goods production is a key factor to determine which policy rule should be followed. Specifically, when the degree of price stickiness at the stage of intermediate-goods production is high, I-GPPIT results in the highest level of welfare among three Taylor-type monetary policy rules thus should be followed by the policymaker. As a comparison, when the degree of price stickiness at the stage of intermediate-goods production is intermediate or low, CPIT replaces I-GPPIT to be the one achieving the highest level of welfare and should be adopted by the policymaker.

In our model, there are four main distortions facing the monetary policy maker who maximizes the global welfare: (1) monopolistic distortion; (2) price dispersion; (3) terms-of-trade distortion; (4) relative-price distortion. Following the literature, we assume that the monopolistic distortions are completely eliminated by governments' subsidies raised in a lump-sum fashion. Thus, when implementing a cooperative monetary policy, the price stickiness at both stages of production is the source of the above-mentioned distortions. After international trade in intermediate inputs is introduced, both home and foreign price dispersions at the stage of final-goods production will lead to an inefficient allocation of labor in any individual country. Furthermore, we find that the welfare loss incurred from price dispersion at both stages of production accounts for a substantial part of aggregate welfare loss. 
To a large degree, the ranking of three Taylor-type monetary policy rules depends on their respective abilities to reduce price dispersions at both stages of production. When the degree of price stickiness at the stage of intermediate-goods production is high, price dispersion at the stage of intermediategoods production causes great distortions. In this circumstance, I-GPPIT outperforms both CPIT and F-GPPIT in stabilizing intermediate-goods PPI inflation rates and should be followed by the policymaker. However, I-GPPIT also performs worst in stabilizing final-goods PPI inflation rates, thus cannot be chosen when the degree of price stickiness is intermediate or low. In our calibrated model, F-GPPIT performs worst in stabilizing intermediate-goods PPI inflation rates and alternates with CPIT to be the one performing best in stabilizing final-goods PPI inflation rates. As a comparison, CPIT strikes a balance in stabilizing intermediate-goods PPI and final-goods PPI inflation rates and achieves the highest level of welfare when the degree of price stickiness is intermediate or low.

The paper is related to a large literature on optimal monetary policy in open economies (for a recent review, see Corsetti et al., 2011). The literature is classified into two strands by the duration of the nominal stickiness. The first strand of the literature is initiated by Obstfeld and Rogoff (2000, 2002), in which nominal wages are set one period in advance. In Obstfeld and Rogoff (2000), the optimal monetary policy can replicate the real allocation under flexible wages and thus is efficient. Obstfeld and Rogoff (2002) extend Obstfeld and Rogoff (2000) to consider the optimal monetary policy in the case of incomplete risk sharing, and show that gains from coordination are quantitatively small. Afterward, the first strand of the literature is extended along the following lines: (1) the elasticity of exchange-rate pass-through (Corsetti and Pesenti, 2005; Devereux and Engel, 2003, 2007; Devereux et al., 2007; Wang and Zou, 2013, 2015); (2) the intratemporal and intertemporal elasticities of substitution (Benigno and Benigno, 2003; Sutherland, 2006); and (3) multiple sectors (Canzoneri et al., 2005; Duarte and Obstfeld, 2008; Shi and Xu, 2007). By comparison, the second strand of the literature is initiated by Clarida et al. (2001, 2002), and Gali and Monacelli (2005) which adopt Calvo-type staggered price-setting and have been a main framework to analyze the properties and macroeconomic implications of various monetary policy regimes. Similarly, the second strand of the literature is also extended in several directions, they are respectively: (1) the elasticity of exchange-rate pass-through (Engel, 2011); (2) the intertemporal and international demand elasticity and the degree of openness (Paoli, 2009a; Pappa, 2004); (3) endogenous portfolio choice (Devereux and Sutherland, 2008); (4) the interaction between the distortions and source of disturbance (Benigno and Benigno, 2006); (5) multiple sectors (Liu and Pappa, 2008); and (6) asset market structures (Benigno, 2009; Paoli, 2009b; Rabitsch, 2012). Our paper is based on Clarida et al. (2001, 2002), and Gali and Monacelli (2005), and features the complete exchange-rate pass through (PCP), complete asset markets, a unity elasticity of substitution between home and foreign goods but a general intertemporal elasticity of substitution, a vertical production and trade structure and home bias in both consumption and production.

The rest of the paper is organized as follows. Section 2 lays out the model. Section 3 derives the steady state, the flexible-price equilibrium and the equilibrium dynamics under sticky prices. Section 4 discusses the problem of monetary policy design. Section 5 concludes.

\section{The model}

The world economy consists of two countries, home $H$ and foreign $F$, each of which has a continuum of households of unit mass $[0,1]$. The production in both countries takes place in two stages, from intermediate goods to final goods. At intermediate-goods production stage, a continuum of home intermediate-goods producers indexed by $j_{i} \in[0,1]$ employ home labor to produce differentiated products, which are demanded by both home and foreign final-goods producers. At final-goods production stage, a continuum of home final-goods producers indexed by $j_{f} \in[0,1]$ use both home and foreign intermediate goods as inputs to produce outputs, which are consumed by households in both countries. The production structure for the foreign is symmetric. Households in both countries trade in a complete set of state-contingent claims, which are denominated in home currency. In the following, foreign variables are marked with an asterisk, subscript $f$ denotes final good, and $i$ denotes intermediate good. 


\subsection{Households}

The representative household $h$ in the home country maximizes the following utility function

$$
\mathbf{E}_{0} \sum_{t=0}^{\infty} \beta^{t} U\left(C_{t}(h), N_{t}(h)\right)=\mathbf{E}_{0} \sum_{t=0}^{\infty} \beta^{t}\left\{\frac{C_{t}(h)^{1-\sigma}}{1-\sigma}-\frac{N_{t}(h)^{1+\varphi}}{1+\varphi}\right\}
$$

in which $\beta \in(0,1)$ is the discount factor, $C_{t}(h)$ is consumption, and $N_{t}(h)$ is labor effort. The consumption $C_{t}(h)$ is a composite of home and foreign final goods:

$$
C_{t}(h)=\left(C_{H t}(h)\right)^{\frac{v}{2}}\left(C_{F t}(h)\right)^{1-\frac{v}{2}}, \quad 0 \leq v \leq 2 .
$$

Following Engel (2011), we assume that both home and foreign households have home bias in their expenditure shares when $v>1$. In addition, $C_{H t}(h)$ and $C_{F t}(h)$ are CES aggregates given respectively by

$$
C_{H t}(h)=\left(\int_{0}^{1} C_{H t}\left(h, j_{f}\right)^{\frac{\xi_{f}-1}{\xi_{f}}} d j_{f}\right)^{\frac{\xi_{f}}{\xi_{f}-1}}, \quad C_{F t}(h)=\left(\int_{0}^{1} C_{F t}\left(h, j_{f}^{*}\right)^{\frac{\xi_{f}-1}{\xi_{f}}} d j_{f}^{*}\right)^{\frac{\xi_{f}}{\xi_{f}-1}} .
$$

in which $\xi_{f}>1$ is the elasticity of substitution between differentiated final goods. Note that in equation (2), we have followed many studies on optimal monetary policy in open economies and assumed that the elasticity of substitution between home and foreign goods is one (see Clarida et al., 2002; Benigno, 2004; Liu and Pappa, 2008; Engel, 2011). However, there is large literature supporting that the elasticity is different from one (Feenstra et al., 2014), and a large number of papers have studied the optimal monetary policy when the elasticity is not equal to one (Corsetti et al., 2011; Paoli, 2009a; Sutherland, 2006; Teo, 2011). Generally speaking, when the elasticity departs from one, the monetary policy maker will care about stabilizing terms-of-trade volatility. Here we stick with the assumption that the elasticity is one to simplify our analysis.

Solving household $h$ 's expenditure-minimization problem gives rise to

$$
\begin{aligned}
& C_{H t}\left(h, j_{f}\right)=\frac{v}{2}\left(\frac{P_{\mathrm{Hft}}\left(j_{f}\right)}{P_{\mathrm{Hft}}}\right)^{-\xi_{f}}\left(\frac{P_{\mathrm{Hft}}}{P_{f t}}\right)^{-1} C_{t}(h), \\
& C_{F t}\left(h, j_{f}^{*}\right)=\left(1-\frac{v}{2}\right)\left(\frac{P_{\mathrm{Fft}}\left(j_{f}^{*}\right)}{P_{\mathrm{Fft}}}\right)^{-\xi_{f}}\left(\frac{P_{\mathrm{Fft}}}{P_{f t}}\right)^{-1} C_{t}(h)
\end{aligned}
$$

where $P_{\mathrm{Hft}}=\left(\int_{0}^{1} P_{\mathrm{Hft}}\left(j_{f}\right)^{1-\xi_{f}} d j_{f}\right)^{\frac{1}{1-\xi_{f}}}$ is home final-goods PPI, $P_{\mathrm{Fft}}=\left(\int_{0}^{1} P_{\mathrm{Fft}}\left(j_{f}^{*}\right)^{1-\xi_{f}} d j_{f}^{*}\right)^{\frac{1}{1-\xi_{f}}}$ is a price index for final goods imported from the foreign country, and $P_{f t}=k^{-1} P_{\mathrm{Hft}}^{v / 2} P_{f f t}^{1-v / 2}, k=(v / 2)^{v / 2}(1-v / 2)^{1-v / 2}$ is home CPI. Household $h$ maximizes equation (1) subject to the following budget constraint

$$
P_{f t} C_{t}(h)+\sum_{s_{t+1} \in \Omega_{t+1}} Z\left(s_{t+1} \mid s_{t}\right) D\left(h, s_{t+1}\right)=W_{t} N_{t}(h)+D\left(h, s_{t}\right)-T_{t}+\Gamma_{t},
$$

in which $D\left(h, s_{t}\right)$ is the nominal payoffs on state-contingent claims for state $s_{t}, Z\left(s_{t+1} \mid s_{t}\right)$ is the state- $s_{t}$ price of a claim that yields one unit of home currency in state $s_{t+1}, W_{t}$ is the nominal wage, $T_{t}$ denotes lump-sum taxes, and $\Gamma_{t}$ denotes aggregate profits accruing from ownership of home firms.

The first-order condition for labor supply is standard and given by

$$
C_{t}(h)^{\sigma} N_{t}(h)^{\varphi}=\frac{W_{t}}{P_{f t}} .
$$


Equation (7) implies that the marginal rate of substitution between leisure and consumption is equal to real wage.

The intertemporal consumption choice is described by

$$
\beta\left(\frac{C_{t+1}(h)}{C_{t}(h)}\right)^{-\sigma} \frac{P_{f t}}{P_{f t+1}}=Q\left(s_{t+1} \mid s_{t}\right)
$$

in which $Q\left(s_{t+1} \mid s_{t}\right) \equiv \frac{Z\left(s_{t+1} \mid s_{t}\right)}{\operatorname{Pr}\left(S_{t+1} \mid s_{t}\right)}$ is the normalized price of the state contingent claim. Equation (8) implies that the intertemporal marginal rate of substitution is equal to the price of the state contingent claim. Taking expectations on both sides of equation (8), we obtain the stochastic Euler equation:

$$
\beta R_{t} \mathbf{E}_{t}\left[\left(\frac{C_{t+1}(h)}{C_{t}(h)}\right)^{-\sigma} \frac{P_{f t}}{P_{f t+1}}\right]=1
$$

where $R_{t}=\left[\mathbf{E}_{t} Q\left(s_{t+1} \mid s_{t}\right)\right]^{-1}$ is the gross nominal return on a riskless one-period bond.

\subsection{Firms and optimal price setting}

Home final goods are produced by a continuum of firms indexed by $j_{f} \in[0,1]$ with the following production function:

$$
Y_{f t}\left(j_{f}\right)=\frac{A_{f t} Y_{H i t}^{\phi}\left(j_{f}\right) Y_{\text {Fit }}^{1-\phi}\left(j_{f}\right)}{\phi^{\phi}(1-\phi)^{1-\phi}}
$$

in which $Y_{\text {Hit }}\left(j_{f}\right)=\left[\int_{0}^{1} Y_{H i t}\left(j_{f}, j_{i}\right)^{\frac{\xi_{i}-1}{\xi_{i}}} d j_{i}\right]^{\frac{\xi_{i}}{\xi_{i}-1}}, Y_{\text {Fit }}\left(j_{f}\right)=\left[\int_{0}^{1} Y_{F i t}\left(j_{f}, j_{i}^{*}\right)^{\frac{\xi_{i}-1}{\xi_{i}}} d j_{i}^{*}\right]^{\frac{\xi_{i}}{\xi_{i j}-1}}$ are home and foreign composite intermediate goods used by $j_{f}$ respectively, $\xi_{i}>1$ is the elasticity of substitution between differentiated intermediate goods, $A_{f t}$ is a common productivity shock to all home final-goods producers, $\phi$ measures the expenditure share of the firm $j_{f}$ on home composite intermediate goods. We assume that the production function facing a foreign final-good producer $j_{f}^{*} \in[0,1]$ also has the same form as equation (10) but the expenditure share on home composite intermediate goods is $1-\phi$ instead. In other words, final-goods producers exhibit home-bias in their production function.

Home intermediate good $j_{i} \in[0,1]$ is produced with a production function that only uses home labor:

$$
Y_{i t}\left(j_{i}\right)=A_{i t} N_{t}\left(j_{i}\right) \text {, }
$$

in which $A_{i t}$ is a common productivity shock to all home intermediate-goods producers.

Let $a_{f t} \equiv \log \left(A_{f t}\right)$, we assume $a_{f t}$ follows the AR(1) process $a_{f t}=\rho_{f} a_{f t-1}+\varepsilon_{f t}$, in which $\varepsilon_{f t} \sim N\left(0, \sigma_{f}^{2}\right)$, $a_{i t} \equiv \log \left(A_{i t}\right)$ possesses the same property, i.e. $a_{i t}=\rho_{i} a_{i t-1}+\varepsilon_{i t}$ and $\varepsilon_{i t}$ is independent of $\varepsilon_{f t}$.

Solving firm $j_{f}^{\prime} s$ cost-minimization problem, ${ }^{8}$ we can obtain its unit cost function: $M C_{f t}=\frac{P_{H i t}^{\phi} p_{f i t}^{1-\phi}}{f_{f t}}$, in which $P_{\text {Hit }}=\left[\int_{0}^{1} P_{H i t}\left(j_{i}\right)^{1-\xi_{i}} d j_{i}\right]^{\frac{1}{1-\xi_{i}}}$ is home intermediate-goods PPI, $P_{\text {Fit }}=\left[\int_{0}^{1} P_{F i t}\left(j_{i}^{*}\right)^{1-\xi_{i}} d j_{i}^{*}\right]^{\frac{1}{1-\xi_{i}}}$ is a price index for intermediate goods imported from the foreign country. The demands for home and foreign intermediate goods $j_{i}$ and $j_{i}^{*}$ of $j_{f}$ are respectively:

$$
Y_{\text {Hit }}\left(j_{f}, j_{i}\right)=\phi\left(\frac{P_{\text {Hit }}\left(j_{i}\right)}{P_{\text {Hit }}}\right)^{-\xi_{i}} \frac{M C_{f t}}{P_{\text {Hit }}} Y_{f t}\left(j_{f}\right) \text {, }
$$

\footnotetext{
8 Following Huang and Liu (2005), we assume all firms take input prices as given but have monopoly power in their own product markets.
} 


$$
Y_{\text {Fit }}\left(j_{f}, j_{i}^{*}\right)=(1-\phi)\left(\frac{P_{\text {Fit }}\left(j_{i}^{*}\right)}{P_{\text {Fit }}}\right)^{-\xi_{\tilde{i}}} \frac{M C_{f t}}{P_{\text {Fit }}} Y_{f t}\left(j_{f}\right) .
$$

We assume that all producers set export prices in their own currency (PCP, for "producercurrency pricing"), thus the law of one price holds. Empirically, many studies have found that the law of one price is violated. ${ }^{9}$ Firms may set their prices in consumers' currency (local-currency pricing or LCP). Betts and Devereux (2000) initially introduce LCP into an open-economy sticky-price model to analyze optimal monetary policy. Under PCP, the exchange-rate pass-through is complete; comparatively, the exchange-rate pass-through is zero under LCP. The difference between PCP and LCP implies different monetary policy prescription (Devereux and Engel, 2003; Devereux et al., 2006; Engel, 2011). Under LCP, when a Calvo pricing mechanism is adopted, a monetary policy maker should consider currency misalignment (Engel, 2011). Admittedly, considering LCP in a model with international trade in intermediate inputs like ours is interesting but complicates our analysis. To facilitate our analysis, we leave LCP out of the model and only consider PCP.

Firms at both stages of production set prices in a staggered fashion, as in Calvo (1983). In each period, a representative firm $j_{f}$ can adjust its prices in both home and foreign markets with probability $1-\theta_{f}$. When the firm $j_{f}$ is able to set its price in period $t$, it chooses $P_{H f t}^{o}\left(j_{f}\right)$ to maximize

$$
\mathbf{E}_{t} \sum_{\tau=t}^{\infty} \theta_{f}^{\tau-t} Q_{t, \tau}\left[P_{H f t}^{o}\left(j_{f}\right)\left(1+\tau_{f}\right)-M C_{f \tau \mid t}\right] Y_{f \tau \mid t}\left(j_{f}\right),
$$

subject to the demand schedule given by

$$
Y_{f \tau \mid t}\left(j_{f}\right)=\frac{v}{2}\left(\frac{P_{\mathrm{H} f t}^{o}\left(j_{f}\right)}{P_{\mathrm{H} f \tau}}\right)^{-\xi f}\left(\frac{P_{\mathrm{H} f \tau}}{P_{f \tau}}\right)^{-1} C_{\tau}+\left(1-\frac{v}{2}\right)\left(\frac{P_{\mathrm{H} f t}^{o}\left(j_{f}\right)}{E_{\tau} P_{\mathrm{H} f \tau}^{*}}\right)^{-\xi_{f}}\left(\frac{P_{\mathrm{H} f \tau}^{*}}{P_{f \tau}^{*}}\right)^{-1} C_{\tau}^{*} .
$$

In expression (14), $Q_{t, \tau}=\beta^{\tau-t}\left(C_{\tau} / C_{t}\right)^{-\sigma}\left(P_{f t} / P_{f \tau}\right)$ is the stochastic discount factor, $\tau_{f}$ denotes a subsidy to all home final-goods producers, $M C_{f \tau \mid t}$ and $Y_{f \tau \mid t}\left(j_{f}\right)$ denote respectively unit cost and output in period $\tau$ for firm $j_{f}$ that last reset its price in period $t$. Note that in equation (15), we have used the fact that aggregate consumption $\int_{0}^{1} C_{\tau}(h) d h$ is equal to consumption per capita $C_{\tau}=C_{\tau}(h)$, and $E_{\tau}$ is period- $\tau$ nominal exchange rate representing the home currency price of one unit of foreign currency. Solving equation (14) yields the optimal pricing choice

$$
P_{\mathrm{H} f t}^{o}\left(j_{f}\right)=\frac{\xi_{f}}{\left(\xi_{f}-1\right)\left(1+\tau_{f}\right)} \frac{\mathbf{E}_{t} \sum_{\tau=t}^{\infty} \theta_{f}^{\tau-t} Q_{t, \tau} M C_{f \tau \mid t} Y_{f \tau \mid t}\left(j_{f}\right)}{\mathbf{E}_{t} \sum_{\tau=t}^{\infty} \theta_{f}^{\tau-t} Q_{t, \tau} Y_{f \tau \mid t}\left(j_{f}\right)},
$$

in which $\frac{\xi_{f}}{\left(\xi_{f}-1\right)\left(1+\tau_{f}\right)}$ is a markup adjusted by subsidy. Thus, firms resetting their prices will choose a price that is, according to Huang and Liu (2005), an effective markup over a weighted average of their current and expected future marginal costs in the periods during which their prices remain effective.

The optimal pricing problem facing a home intermediate-good producer $j_{i} \in[0,1]$ can be described similarly, it is

$$
P_{H i t}^{o}\left(j_{i}\right)=\frac{\xi_{i}}{\left(\xi_{i}-1\right)\left(1+\tau_{i}\right)} \frac{\mathbf{E}_{t} \sum_{\tau=t}^{\infty} \theta_{i}^{\tau-t} Q_{t, \tau} M C_{i \tau \mid t} Y_{i \tau \mid t}\left(j_{i}\right)}{\mathbf{E}_{t} \sum_{\tau=t}^{\infty} \theta_{i}^{\tau-t} Q_{t, \tau} Y_{i \tau \mid t}\left(j_{i}\right)},
$$

\footnotetext{
9 The literature is large, we name just a few. For example, see Engel (1999), and Atkeson and Burstein (2008).
} 
in which $\frac{\xi_{i}}{\left(\xi_{i}-1\right)\left(1+\tau_{i}\right)}$ is an effective markup, $\theta_{i}$ is the probability with which a given intermediate-good producer's price remains unchanged from the previous period, $M C_{i \tau \mid t}=\frac{W_{\tau}}{A_{i \tau}}$ and $Y_{i \tau \mid t}\left(j_{i}\right)$ are respectively the period- $\tau$ unit cost and output facing firm $j_{i}$ that last reset its price in period $t$; the output $Y_{i \tau \mid t}\left(j_{i}\right)$ is given by

$$
Y_{i \tau \mid t}\left(j_{i}\right)=\phi\left(\frac{P_{H i t}^{o}\left(j_{i}\right)}{P_{H i \tau}}\right)^{-\xi_{i}} \frac{M C_{f \tau}}{P_{H i \tau}} \int_{0}^{1} Y_{f \tau}\left(j_{f}\right) d j_{f}+(1-\phi)\left(\frac{P_{H i t}^{o}\left(j_{i}\right)}{E_{\tau} P_{H i \tau}^{*}}\right)^{-\xi i} \frac{M C_{f \tau}^{*}}{P_{H i \tau}^{*}} \int_{0}^{1} Y_{f \tau}^{*}\left(j_{f}^{*}\right) d j_{f}^{*}
$$

\section{Equilibrium}

Before proceeding, we first define home final-goods terms of trade and intermediate-goods terms of trade as $S_{f t}=\frac{P_{\text {fft }}}{P_{\text {Hft }}}$ and $S_{i t}=\frac{P_{\text {fit }}}{P_{\text {Hit }}}$, respectively, i.e. the price of foreign final (intermediate) goods in terms of home final (intermediate) goods.

Final-goods market clearing condition in the home country is

$$
Y_{f t} \equiv\left(\int_{0}^{1} Y_{f t}\left(j_{f}\right)^{\frac{\xi_{f f}-1}{\xi_{f}}} d j_{f}\right)^{\frac{\xi_{f}}{\xi_{f}-1}}=\frac{v}{2} \frac{P_{f t}}{P_{\mathrm{Hft}}} C_{t}+\left(1-\frac{v}{2}\right) \frac{P_{f t}^{*}}{P_{\mathrm{Hft}}^{*}} C_{t}^{*}=k^{-1}\left(\frac{v}{2} S_{f t}^{1-\frac{v}{2}} C_{t}+\left(1-\frac{v}{2}\right) S_{f t}^{\frac{v}{2}} C_{t}^{*}\right)
$$

Similarly, intermediate-goods market clearing condition in the home country is

$$
Y_{i t} \equiv\left(\int_{0}^{1} Y_{i t}\left(j_{i}\right)^{\frac{\xi_{i}-1}{\xi_{i}}} d j_{i}\right)^{\frac{\xi_{i}}{\xi_{i}-1}}=\phi \frac{M C_{f t}}{P_{H i t}} Y_{f t} D_{f t}+(1-\phi) \frac{M C_{f t}^{*}}{P_{H i t}^{*}} Y_{f t}^{*} D_{f t}^{*}=\frac{\phi}{A_{f t}} S_{i t}^{1-\phi} Y_{f t} D_{f t}+\frac{1-\phi}{A_{f t}^{*}} S_{i t}^{\phi} Y_{f t}^{*} D_{f t}^{*}
$$

in which $D_{f t} \equiv \int_{0}^{1}\left(\frac{P_{H f f}\left(j_{f f}\right)}{P_{H f t}}\right)^{-\xi_{f}} d j_{f}$, and $D_{f t}^{*} \equiv \int_{0}^{1}\left(\frac{P_{f f t}^{*}\left(j_{f}^{*}\right)}{P_{F f t}^{*}}\right)^{-\xi_{f}} d j_{f}^{*}$ are home and foreign price dispersions at the stage of final-goods production caused by staggered price setting.

Home aggregate employment is the sum of labor demands of home intermediate-goods producers:

$$
N_{t}=\int_{0}^{1} N_{t}\left(j_{i}\right) d j_{i}=\frac{Y_{i t}}{A_{i t}} D_{i t}
$$

in which $D_{i t}=\int_{0}^{1}\left(\frac{P_{\text {Hit }}\left(j_{j i}\right)}{P_{\text {Hit }}}\right)^{-\xi_{i}} d j_{i}$ is home price dispersion at the stage of intermediate-goods production.

By combining equation (9) with its foreign counterpart and assuming symmetric initial conditions, we obtain the familiar risk-sharing condition:

$$
\left(\frac{C_{t}}{C_{t}^{*}}\right)^{\sigma}=\mathbb{Q}_{t}=S_{f t}^{v-1}
$$

where $\mathbb{Q}_{t}=\frac{E_{t} P_{f t}^{*}}{P_{f t}}$ denotes the real exchange rate. ${ }^{10}$ In a complete market, the trading between the home and foreign households ensures that the marginal utility of consumption brought by one unit of home currency is the same as that brought by one unit of foreign currency.

\footnotetext{
${ }^{10}$ Note the presence of home bias in consumption leads to deviations from purchasing power parity even under PCP.
} 


\subsection{The steady state}

Our sticky-price equilibrium dynamics are described by the deviation of the log of the variable from its steady state. Thus, it is convenient to introduce the steady state as a beginning. The steady state follows when $A_{f t}=A_{i t}=A_{f t}^{*}=A_{i t}^{*}=1$. The presence of monopoly power at both stages of production implies that there exists a steady-state markup distortion. To obtain an efficient steady state, we assume that the government can raise a tax in a lump-sum fashion and subsidize the production at both stages.

In the efficient steady state, home final-goods terms of trade and intermediate-goods terms of trade are respectively: $S_{f}=\left(\frac{E W^{*}}{W}\right)^{(2 \phi-1)}$ and $S_{i}=\frac{E W^{*}}{W}$, the real exchange rate is $\mathbb{Q}=\left(\frac{E W^{*}}{W}\right)^{(2 \phi-1)(v-1)}$, home consumption wage is $\frac{W}{P_{f}}=k\left(\frac{E W^{*}}{W}\right)^{-\frac{v}{2}(1-\phi)-\left(1-\frac{v}{2}\right) \phi}$.

Thus from equations ( 7 ) and the expression of home consumption wage, we have

$$
N^{\varphi} C^{\sigma}=k\left(\frac{E W^{*}}{W}\right)^{-\frac{v}{2}(1-\phi)-\left(1-\frac{v}{2}\right) \phi} .
$$

From equation (19) and its foreign counterpart, equations (20) and (21), we can obtain home employment after using the expressions of home final-goods and intermediate-goods terms of trade

$$
\begin{aligned}
N= & k^{-1} \phi\left(\frac{E W^{*}}{W}\right)^{1-\phi}\left[\frac{v}{2}\left(\frac{E W^{*}}{W}\right)^{\left(1-\frac{v}{2}\right)(2 \phi-1)} C+\left(1-\frac{v}{2}\right)\left(\frac{E W^{*}}{W}\right)^{\frac{v}{2}(2 \phi-1)} C^{*}\right] \\
& +k^{-1}(1-\phi)\left(\frac{E W^{*}}{W}\right)^{\phi}\left[\left(1-\frac{v}{2}\right)\left(\frac{E W^{*}}{W}\right)^{\frac{v}{2}(1-2 \phi)} C+\frac{v}{2}\left(\frac{E W^{*}}{W}\right)^{\left(1-\frac{v}{2}\right)(1-2 \phi)} C^{*}\right]
\end{aligned}
$$

From equation (22) and the expression of the real exchange rate, the risk-sharing condition can be expressed as

$$
\left(\frac{C}{C^{*}}\right)^{\sigma}=\left(\frac{E W^{*}}{W}\right)^{(2 \phi-1)(v-1)} .
$$

The efficient steady state can be determined by solving 5 equations jointly. They are equation (23) and its foreign counterpart, equation (24) and its foreign counterpart, and equation (25) respectively.

In the efficient steady state, both home final-goods terms of trade and intermediate-goods terms of trade are unity, home households consume the same amount as foreign households, i.e. $C=C^{*}=k^{\frac{1+\varphi}{\sigma+\varphi}}$. In addition, they also supply the same amount of labor, i.e. $N=N^{*}=k^{\frac{1-\sigma}{\sigma+\varphi}}$.

\subsection{The flexible-price equilibrium}

In the following, a lower-case variable with an upper bar represents the deviation of the $\log$ of the corresponding flexible-price variable from its steady-state value. When prices are flexible, we can follow the same steps as in obtaining the steady state to solve the flexible-price equilibrium. To get an efficient flexible-price equilibrium, we also assume that the markup distortions at both stages of production can be eliminated by government's subsidies. After some algebra, we can get the log-linearized version of equation (23)'s analog in the flexible-price equilibrium, which is

$$
\begin{aligned}
\phi \bar{n}_{t}+\sigma \bar{c}_{t}= & \left(1-\frac{v}{2}\right) a_{f t}^{*}+\frac{v}{2} a_{f t}+\left[1-\frac{v}{2}(1-\phi)-\left(1-\frac{v}{2}\right) \phi\right] a_{i t} \\
& +\left[\frac{v}{2}(1-\phi)+\left(1-\frac{v}{2}\right) \phi\right] a_{i t}^{*}-\left[\frac{v}{2}(1-\phi)+\left(1-\frac{v}{2}\right) \phi\right] \bar{\omega}_{t}
\end{aligned}
$$


in which $\bar{\omega}_{t} \equiv d \log \left(\frac{\bar{E} \bar{W}^{*}}{\bar{W}}\right)$. Similarly, the log-linearized version of equation (24)'s analog in the flexibleprice equilibrium is given by

$$
\begin{aligned}
\bar{n}_{t}= & {\left[2 \varphi(1-\varphi)+v\left(1-\frac{v}{2}\right)(1-2 \phi)^{2}\right]\left(a_{i t}-a_{i t}^{*}\right)-a_{i t}-\left[\phi+v\left(1-\frac{v}{2}\right)(1-2 \phi)\right] a_{f t} } \\
& -\left[(1-\phi)-v\left(1-\frac{v}{2}\right)(1-2 \phi)\right] a_{f t}^{*}+\left[\frac{v}{2} \varphi+\left(1-\frac{v}{2}\right)(1-\phi)\right] \bar{c}_{t} \\
& +\left[\frac{v}{2}(1-\phi)+\left(1-\frac{v}{2}\right) \phi\right] \bar{c}_{t}^{*}+\left[2 \varphi(1-\phi)+v\left(1-\frac{v}{2}\right)(1-2 \phi)^{2}\right] \bar{\omega}_{t} .
\end{aligned}
$$

The log-linearized equation representing the risk-sharing condition in the flexible-price equilibrium is

$$
\sigma\left(\bar{c}_{t}-\bar{c}_{t}^{*}\right)=(v-1)\left(a_{f t}-a_{f t}^{*}\right)+(v-1)(2 \phi-1)\left(a_{i t}-a_{i t}^{*}+\bar{\omega}_{t}\right) .
$$

Equation (26) and its foreign counterpart, equation (27) and its foreign analog, along with equation (28), constitute the flexible-price equilibrium system whose solution is relegated to Appendix S1 that accompanies the paper.

\subsection{Equilibrium dynamics under sticky prices}

In this part, we express the sticky-price equilibrium as a log-linear approximation around the steady state. In the following, a lower-case variable refers to the $\log$ deviation of the corresponding upper-case variable from its steady state value.

Log-linearization of the home CPI expression around the steady state yields

$$
p_{f t}=\frac{v}{2} p_{H f t}+\left(1-\frac{v}{2}\right) p_{f f t}=p_{H f t}+\left(1-\frac{v}{2}\right) s_{f t} .
$$

Thus, home CPI inflation, $\pi_{f t}=p_{f t}-p_{f t-1}$, and final-goods PPI inflation are related according to the following expression

$$
\pi_{f t}=\pi_{H f t}+\left(1-\frac{v}{2}\right) \Delta s_{f t},
$$

in which $\Delta s_{f t}=s_{f t}-s_{f t-1}$. From equation (30), the difference between the home CPI inflation and the final-goods PPI inflation depends on the percentage change in the home final-goods terms of trade, with the magnitude of dependence given by the degree of home bias.

The presence of home bias implies that the purchasing power parity does not hold. The real exchange rate can be expressed as

$$
q_{f t}=e_{t}+p_{f t}^{*}-p_{f t}=(v-1) s_{f t} .
$$

Therefore, when home households have home bias in consumption $(v>1)$, the deterioration of the home final-goods terms of trade results in the depreciation of the real exchange rate.

Log-linearization of equation (19) yields

$$
y_{f t}=\frac{v}{2} C_{t}+\left(1-\frac{v}{2}\right) C_{t}^{*}+v\left(1-\frac{v}{2}\right) S_{f t},
$$

which implies that, besides global consumption, the deterioration of the home final-goods terms of trade will also boost home final-goods output. 
The risk-sharing condition (22) implies that home consumption is related to foreign consumption and the home final-goods terms of trade by

$$
c_{t}=c_{t}^{*}+\left(\frac{v-1}{\sigma}\right) s_{f t}
$$

From equation (32) and its foreign counterpart, equation (33), we have

$$
s_{f t}=\frac{y_{f t}-y_{f t}^{*}}{\Sigma},
$$

in which $\Sigma \equiv(v-1)^{2} / \sigma+2 v(1-v / 2)$. Equation (34) implies that an increase in home final-goods output relative to that of the foreign country impairs its terms of trade.

Let $V_{t}=P_{\mathrm{Hit}} / P_{\mathrm{Hft}}$ be the relative price of home intermediate goods in terms of home final goods. Then we have

$$
s_{i t}=p_{\text {Fit }}-p_{\text {Hit }}=v_{t}^{*}-v_{t}+s_{f t},
$$

in which $v_{t}^{*}=p_{\text {Fit }}^{*}-p_{\mathrm{fft}}^{*}$ is the $\log$ of the foreign relative price of intermediate goods in terms of final goods.

The Calvo price-setting mechanism implies that aggregate price level of home final goods evolves as: $P_{\mathrm{Hft}}=\left[\theta_{f} P_{\mathrm{Hft}-1}^{1-\xi_{f}}+\left(1-\theta_{f}\right) P_{\mathrm{Hft}}^{1-\xi_{f}}\right]^{\frac{1}{1-\xi_{f}}}$. Following the familiar steps in the literature, we can obtain a New Keynesian Phillips curve to describe the motion of the home final-goods PPI inflation:

$$
\pi_{H f t}=\delta_{f}\left[\phi \tilde{v}_{t}+(1-\phi) \tilde{v}_{t}^{*}+\frac{(1-\phi)}{\Sigma}\left(\tilde{y}_{f t}-\tilde{y}_{f t}^{*}\right)\right]+\beta \mathbf{E}_{t} \pi_{H f t+1},
$$

in which $\delta_{f} \equiv\left(1-\theta_{f}\right)\left(1-\beta \theta_{f}\right) / \theta_{f}$, a variable with tilde denotes the deviation of the $\log$ of the variable from the corresponding value in flexible-price equilibrium.

Similarly, we can derive equation (36)'s foreign counterpart, it is

$$
\pi_{f f t}^{*}=\delta_{f}\left[\phi \tilde{v}_{t}^{*}+(1-\phi) \tilde{v}_{t}-\frac{(1-\phi)}{\Sigma}\left(\tilde{y}_{f t}-\tilde{y}_{f t}^{*}\right)\right]+\beta \mathbf{E}_{t} \pi_{f f t+1}^{*}
$$

At the stage of the intermediate-goods production, there are also two New Keynesian Phillips curves to describe the home and foreign intermediate-goods PPI inflation rates; they are respectively

$$
\begin{aligned}
& \pi_{H i t}=\delta_{i}\left\{2 \varphi \phi(1-\phi)\left(\tilde{v}^{*}-\tilde{v}_{t}\right)-\tilde{v}_{t}+\left[(\sigma+\varphi \phi)+\frac{\Pi}{\Sigma}\right] \tilde{y}_{f t}+\left[\varphi(1-\phi)-\frac{\Pi}{\Sigma}\right] \tilde{y}_{f t}^{*}\right\}+\beta \mathbf{E}_{t} \pi_{H i t+1}, \\
& \pi_{\text {Fit }}^{*}=\delta_{i}\left\{2 \varphi \phi(1-\phi)\left(\tilde{v}-\tilde{v}_{t}^{*}\right)-\tilde{v}_{t}^{*}+\left[(\sigma+\varphi \phi)+\frac{\Pi}{\Sigma}\right] \tilde{y}_{f t}^{*}+\left[\varphi(1-\phi)-\frac{\Pi}{\Sigma}\right] \tilde{y}_{f t}\right\}+\beta \mathbf{E}_{t} \pi_{\mathrm{Fit}+1}^{*},
\end{aligned}
$$

in which $\delta_{i} \equiv\left(1-\theta_{i}\right)\left(1-\beta \theta_{i}\right) / \theta_{i}, \Pi \equiv 2 \varphi \phi(1-\phi)-(1-v / 2)(\sigma-1) v$.

Thus, as predicted by Clarida et al. (2002), the introduction of international trade in intermediate inputs indeed results in an additional effect of openness on marginal cost. In Clarida et al. (2002) and Engel (2011), the real marginal cost only depends on home and foreign output gaps. Comparatively, in our model, the real marginal costs at both stages of production are determined not only by home and foreign output gaps but also by home and foreign relative-price gaps.

In addition, there is an identity to associate the change in the home relative-price gap with the home final-goods inflation, home intermediate-goods inflation, and home relative price in the flexibleprice equilibrium; it is 


$$
\tilde{v}_{t}=\tilde{v}_{t-1}+\pi_{H i t}-\pi_{H f t}-\Delta \bar{v}_{t},
$$

in which $\Delta \overline{v_{t}}=\overline{v_{t}}-\bar{v}_{t-1}$, and

$$
\bar{v}_{t}=a_{f t}+\Xi\left(a_{f t}-a_{f t}^{*}\right)-\digamma\left(a_{i t}-a_{i t}^{*}\right),
$$

where $\Xi \equiv \frac{\phi(1-\varphi)(1-2 \Lambda)}{(1-2 \varphi)(1+2 \phi \Lambda)}, \digamma \equiv \frac{(1+\phi)(1-\varphi)}{(1+2 \phi \Lambda)}, \Lambda$ is an expression which is formally defined in the derivation of the flexible-price equilibrium and transcribed as $\Lambda \equiv 2 \phi(1-\phi)+v\left(1-\frac{v}{2}\right)(1-2 \phi)^{2}+(v-1)^{2}(1-2 \phi)^{2} / 2 \sigma$.

Similarly, the change in the foreign relative-price gap can be written as

$$
\tilde{v}_{t}^{*}=\tilde{v}_{t-1}^{*}+\pi_{F i t}^{*}-\pi_{F f t}^{*}-\Delta \bar{v}_{t}^{*}
$$

where $\Delta \bar{v}_{t}^{*}=\bar{v}_{t}^{*}-\bar{v}_{t-1}^{*}$, and

$$
\bar{v}_{t}^{*}=a_{f t}^{*}-\Xi\left(a_{f t}-a_{f t}^{*}\right)+\digamma\left(a_{i t}-a_{i t}^{*}\right) .
$$

Log-linearizing the stochastic Euler equation (9) around the steady state and using equations (30), (32), (33) and (34), then rewriting the resulting equation in terms of home final-goods output gap, we can derive a dynamic IS equation for the home country:

$$
\tilde{y}_{f t}=\mathbf{E}_{t} \tilde{y}_{f t+1}-\frac{\Sigma}{\sigma \Sigma-\Upsilon}\left(i_{t}-\mathbf{E}_{t} \pi_{H f t+1}-\bar{r} r_{t}\right),
$$

in which $i_{t} \equiv \ln R_{t}$ is home nominal interest rate, $\mathrm{\Upsilon} \equiv\left(1-\frac{v}{2}\right)(\sigma-1) v$ and

$$
\begin{aligned}
\overline{r r}_{t} \equiv & \rho+\frac{\Upsilon}{\Sigma} \mathbf{E}_{t}\left\{\Delta y_{f t+1}^{*}\right\}+\frac{\sigma \Sigma-\Upsilon}{\Sigma}\left[\frac{1+\varphi}{2(\sigma+\varphi)}-\frac{\Sigma \digamma(1-2 \phi)}{2(1-\phi)}\right]\left(\rho_{i}-1\right) a_{i t} \\
& +\frac{\sigma \Sigma-\Upsilon}{\Sigma}\left\{\left[\frac{1+\varphi}{2(\sigma+\varphi)}+\frac{\Sigma \digamma(1-2 \phi)}{2(1-\phi)}\right]\left(\rho_{i}^{*}-1\right) a_{i t}^{*}+\left[\frac{1+\varphi}{2(\sigma+\varphi)}+\frac{\Sigma \digamma}{2(1-\phi)}\right]\left(\rho_{f}-1\right) a_{f t}\right\} \\
& +\frac{\sigma \Sigma-\Upsilon}{\Sigma}\left[\frac{1+\varphi}{2(\sigma+\varphi)}-\frac{\Sigma \digamma}{2(1-\phi)}\right]\left(\rho_{f}^{*}-1\right) a_{f t}^{*}
\end{aligned}
$$

is home real interest rate in the flexible-price equilibrium. ${ }^{11}$

Similarly, we can derive equation (42)'s foreign counterpart, it is

$$
\tilde{y}_{f t}^{*}=\mathbf{E}_{t} \tilde{y}_{f t+1}^{*}-\frac{\Sigma}{\sigma \Sigma-\Upsilon}\left(i_{t}^{*}-\mathbf{E}_{t} \pi_{f f t+1}^{*}-\overline{r r}_{t}^{*}\right)
$$

where $i_{t}^{*}=i_{t}-\mathbf{E}_{t}\left\{\Delta e_{t+1}\right\}$ is foreign nominal interest rate, ${ }^{12}$ and

$$
\begin{aligned}
\overline{r r}_{t}^{*} \equiv & \rho+\frac{\Upsilon}{\Sigma} \mathbf{E}_{t}\left\{\Delta y_{f t+1}\right\}+\frac{\sigma \Sigma-\Upsilon}{\Sigma}\left[\frac{1+\varphi}{2(\sigma+\varphi)}+\frac{\Sigma \digamma(1-2 \phi)}{2(1-\phi)}\right]\left(\rho_{i}-1\right) a_{i t} \\
& +\frac{\sigma \Sigma-\Upsilon}{\Sigma}\left\{\left[\frac{1+\varphi}{2(\sigma+\varphi)}-\frac{\Sigma \digamma(1-2 \phi)}{2(1-\phi)}\right]\left(\rho_{i}^{*}-1\right) a_{i t}^{*}+\left[\frac{1+\varphi}{2(\sigma+\varphi)}-\frac{\Sigma \digamma}{2(1-\phi)}\right]\left(\rho_{f}-1\right) a_{f t}\right\} \\
& +\frac{\sigma \Sigma-\Upsilon}{\Sigma}\left[\frac{1+\varphi}{2(\sigma+\varphi)}+\frac{\Sigma \digamma}{2(1-\phi)}\right]\left(\rho_{f}^{*}-1\right) a_{f t}^{*}
\end{aligned}
$$

is foreign real interest rate in the flexible-price equilibrium.

\footnotetext{
${ }^{11}$ In equation (43), $\rho \equiv-\log \beta$ can be interpreted as the households' discount rate.

12 This expression is the familiar uncovered interest-parity condition.
} 
To close the model, we need to supplement equations (36)-(42) and equation (44) with two equations describing how the nominal interest rates in the home and foreign evolve over time, i.e., how monetary policies in both countries are conducted. We will introduce various monetary policy rules in the subsequent sections.

\section{Monetary policy design}

In a standard closed-economy New Keynesian model without cost-push shocks, when the monopolistic distortions are eliminated by government's production subsidies raised in a lump-sum fashion, the optimal monetary policy can simultaneously close the output gap and realize a zero inflation at all times, i.e., there is no trade-off between closing the output gap and stabilizing the inflation (Gali, 2008). However, when cost-push shocks, such as variations in desired price markups or exogenous variations in wage markups, are introduced into the model, the "divine coincidence" (Blanchard and Gali, 2007) breaks down. Generally, when the model is extended to consider multiple nominal rigidities (Erceg et al., 2000) or multiple sectors (Huang and Liu, 2005), the trade-off facing the central bank appears. ${ }^{13}$ In open-economy New Keynesian monetary models, such as Clarida et al. (2002), Gali and Monacelli (2005), and Engel (2011), the "divine coincidence" also holds when there are no cost-push shocks. Can the same conclusion be carried over to a similar model with international trade in intermediate inputs?

Before we proceed to answer the above question, it is helpful to make clear the definition of Pareto optimal equilibrium allocation. As in Huang and Liu (2005), when both governments in the home and foreign can eliminate distortions involving the firms' monopoly power at both stages using the production subsidies raised in a lump-sum fashion, furthermore, if all firms can adjust their prices freely, the resulting equilibrium allocation is Pareto optimal. In other words, an equilibrium allocation is Pareto optimal if output gaps, inflation rates and relative-price gaps are zero at the same time. Then, we have

Proposition 1. In a model with international trade in intermediate inputs, it is impossible to implement the flexible-price equilibrium allocation.

Proof. We prove the proposition by contradiction. Suppose there were a monetary policy with which the flexible-price equilibrium allocation can be implemented. Then $\tilde{y}_{f t}=\tilde{y}_{f t}^{*}=\tilde{v}_{t}=\tilde{v}_{t}^{*}$ for all $t$. It follows from equations (36)-(39) that $\pi_{\mathrm{Hft}}=\pi_{\mathrm{Fft}}^{*}=\pi_{\mathrm{Hit}}=\pi_{\mathrm{Fit}}^{*}=0$ for all $t$. However, from equations (40) and (41), we know $\pi_{H i t}-\pi_{H f t}=\Delta \bar{v}_{t}=\Delta a_{f t}+\Xi\left(\Delta a_{f t}-\Delta a_{f t}^{*}\right)-\digamma\left(\Delta a_{i t}-\Delta a_{i t}^{*}\right)$ and $\pi_{\mathrm{Fit}}^{*}-\pi_{\mathrm{fft}}^{*}=\Delta \bar{v}_{t}^{*}=\Delta a_{\mathrm{ft}}^{*}-\Xi\left(\Delta a_{f t}-\Delta a_{f t}^{*}\right)+\digamma\left(\Delta a_{i t}-\Delta a_{i t}^{*}\right)$, contradicting that $\pi_{\mathrm{Hft}}=\pi_{\mathrm{fft}}^{*}=\pi_{\mathrm{Hit}}=\pi_{\mathrm{Fit}}^{*}=0$ for all $t$.

By considering the production openness, ${ }^{14}$ our result stands in contrast to what is obtained in the literature. Comparing with Clarida et al. (2002), Gali and Monacelli (2005), and Engel (2011), the "divine coincidence" breaks down even if there are no cost-push shocks. When labor is not an input factor in final-goods producers' production function, in Huang and Liu (2005), the relative price of intermediate goods does not respond to the shocks, consequently, the flexible-price equilibrium allocation is also attainable. In our model, ${ }^{15}$ both home and foreign relative prices of intermediate goods respond to the shocks. As a result, it is impossible to implement the flexible-price equilibrium allocation. Note that the conclusion holds even if there is no international trade in intermediate goods. ${ }^{16}$ In addition, in Huang and Liu (2005), if the two sectors are affected by identical shocks, the flexible-price equilibrium allocation can be replicated. By a casual inspection of the expressions of $\bar{v}_{t}$ and $\bar{v}_{t}^{*}$, we know the conclusion cannot be carried over to an open-economy model.

\footnotetext{
${ }^{13}$ Recently, in an estimated DSGE model of the U.S. economy, Justiniano et al. (2013) find that there is no trade-off between inflation and output stabilization when the major driver of observed economic fluctuations is not from exogenous movements in workers' market power. Otherwise, the trade-off appears but has negligible effects on the equilibrium when optimal monetary policy is conducted.

${ }^{14}$ We borrow the phrase from Monacelli (2013).

${ }^{15}$ No labor input is required in final-goods producers' production function.

${ }^{16}$ It corresponds to the situation in which $\phi=1$.
} 


\subsection{Optimal monetary policy}

Since it is impossible for home and foreign central banks to attain the flexible-price allocation, it is advisable for us to analyze policy choices capable of achieving second best outcomes. To evaluate a second-best monetary policy, we need to define a welfare criterion for the central banks. Following a well established tradition in the literature (e.g., Woodford, 2003), we take a second-order approximation to the joint utility function of home and foreign households. ${ }^{17}$ Thus, we only focus on cooperative monetary policy.

As shown in Appendix S1, a cooperative monetary policymaker wishes to minimize the following welfare loss function

$$
\mathbf{W}=\frac{1}{2} \mathbf{E}_{0} \sum_{t=0}^{\infty} \beta^{t} \mathbf{X}_{t}+\text { t.i.p. }+O\left(\|a\|^{3}\right),
$$

in which

$$
\begin{aligned}
\mathbf{X}_{t}= & \frac{\xi_{i}}{\delta_{i}}\left(\pi_{\text {Hit }}^{2}+\pi_{\mathrm{fit}}^{* 2}\right)+\frac{\xi_{f}}{\delta_{f}}\left(\pi_{\mathrm{fft}}^{2}+\pi_{\mathrm{fft}}^{* 2}\right)+8(1+\varphi) \phi^{2}(1-\phi)^{2}\left(\tilde{v}_{t}^{2}-2 \tilde{v}_{t} \tilde{v}_{t}^{*}+\tilde{v}_{t}^{* 2}\right) \\
& +\frac{1}{2}\left[(\sigma+\varphi)+(1+\varphi)\left((2 \phi-1)+\frac{4 \phi(1-\phi)}{\Sigma}\right)^{2}-\frac{(1-\sigma)(v-1)^{2}}{(\sigma \Sigma)^{2}}\right]\left(\tilde{y}_{f t}^{2}+\tilde{y}_{f t}^{* 2}\right) \\
& +\left[(\sigma+\varphi)-(1+\varphi)\left((2 \phi-1)+\frac{4 \phi(1-\phi)}{\Sigma}\right)^{2}+\frac{(1-\sigma)(v-1)^{2}}{(\sigma \Sigma)^{2}}\right] \tilde{y}_{f t} \tilde{y}_{f t}^{*} \\
& -4 \phi(1-\phi)\left[(1+\varphi)\left((2 \phi-1)+\frac{4 \phi(1-\phi)}{\Sigma}\right)\left(\tilde{y}_{f t}-\tilde{y}_{f t}^{*}\right)+\frac{(1-2 \Lambda)}{\Sigma(1-2 \phi)}\left(\bar{y}_{f t}-\bar{y}_{f t}^{*}\right)\right]\left(\tilde{v}_{t}-\tilde{v}_{t}^{*}\right) \\
& -\left[\frac{(1-\sigma)(v-1)^{2}}{(\sigma \Sigma)^{2}}-\frac{(1-2 \Lambda)(4 \phi(1-\phi)-\Sigma(1-2 \phi))}{\Sigma^{2}(1-2 \phi)}\right]\left(\tilde{y}_{f t}-\tilde{y}_{f t}^{*}\right)\left(\bar{y}_{f t}-\bar{y}_{f t}^{*}\right)
\end{aligned}
$$

t.i.p. stands for the terms independent of policy and $O\left(\|a\|^{3}\right)$ collects all terms of third order or higher.

The expected period welfare loss function can be written as

$$
\begin{aligned}
\mathbf{L}= & \frac{\xi_{i}}{2 \delta_{i}}\left(\operatorname{var}\left(\pi_{H i t}\right)+\operatorname{var}\left(\pi_{F i t}^{*}\right)\right)+\frac{\xi_{f}}{2 \delta_{f}}\left(\operatorname{var}\left(\pi_{\mathrm{Hft}}\right)+\operatorname{var}\left(\pi_{\mathrm{Ft}}^{*}\right)\right) \\
& +4(1+\varphi) \phi^{2}(1-\phi)^{2}\left[\operatorname{var}\left(\tilde{v}_{t}\right)+\operatorname{var}\left(\tilde{v}_{t}^{*}\right)-2 \operatorname{cov}\left(\tilde{v}_{t}, \tilde{v}_{t}^{*}\right)\right] \\
& +\frac{1}{4}\left[(\sigma+\varphi)+(1+\varphi)\left((2 \phi-1)+\frac{4 \phi(1-\phi)}{\Sigma}\right)^{2}-\frac{(1-\sigma)(v-1)^{2}}{(\sigma \Sigma)^{2}}\right]\left(\operatorname{var}\left(\tilde{y}_{f t}\right)+\operatorname{var}\left(\tilde{y}_{f t}^{*}\right)\right) \\
& +\frac{1}{2}\left[(\sigma+\varphi)-(1+\varphi)\left((2 \phi-1)+\frac{4 \phi(1-\phi)}{\Sigma}\right)^{2}+\frac{(1-\sigma)(v-1)^{2}}{(\sigma \Sigma)^{2}}\right] \operatorname{cov}\left(\tilde{y}_{f t}, \tilde{y}_{f t}^{*}\right) \\
& -2(1+\varphi) \phi(1-\phi)\left[(2 \phi-1)+\frac{4 \phi(1-\phi)}{\Sigma}\right]\left[\operatorname{cov}\left(\tilde{y}_{f t}, \tilde{v}_{t}\right)-\operatorname{cov}\left(\tilde{y}_{f t}, \tilde{v}_{t}^{*}\right)-\operatorname{cov}\left(\tilde{y}_{f t}^{*}, \tilde{v}_{t}\right)+\operatorname{cov}\left(\tilde{y}_{f t}^{*}, \tilde{v}_{t}^{*}\right)\right] \\
& -\frac{1}{2}\left[\frac{(1-\sigma)(v-1)^{2}}{(\sigma \Sigma)^{2}}-\frac{(1-2 \Lambda)(4 \phi(1-\phi)-\Sigma(1-2 \phi))}{\Sigma^{2}(1-2 \phi)}\right]\left[\operatorname{cov}\left(\tilde{y}_{f t}, \bar{y}_{f t}\right)-\operatorname{cov}\left(\tilde{y}_{f t}, \bar{y}_{f t}^{*}\right)\right] \\
& +\frac{1}{2}\left[\frac{(1-\sigma)(v-1)^{2}}{(\sigma \Sigma)^{2}}-\frac{(1-2 \Lambda)(4 \phi(1-\phi)-\Sigma(1-2 \phi))}{\Sigma^{2}(1-2 \phi)}\right]\left[\operatorname{cov}\left(\tilde{y}_{f t}^{*}, \bar{y}_{f t}\right)-\operatorname{cov}\left(\tilde{y}_{f t}^{*}, \bar{y}_{f t}^{*}\right)\right] \\
& -\frac{2 \phi(1-\phi)(1-2 \Lambda)}{\Sigma(1-2 \phi)}\left[\operatorname{cov}\left(\tilde{v}_{t}, \bar{y}_{f t}\right)-\operatorname{cov}\left(\tilde{v}_{t}, \bar{y}_{f t}^{*}\right)-\operatorname{cov}\left(\tilde{v}_{t}^{*}, \bar{y}_{f t}\right)+\operatorname{cov}\left(\tilde{v}_{t}^{*}, \bar{y}_{f t}^{*}\right)\right]
\end{aligned}
$$

\footnotetext{
${ }^{17}$ As in Engel (2011), it is difficult to derive the loss function for a Nash case and define a Nash policy game. Thus, we leave the topic as further research.
} 
Comparing with Engel (2011), ${ }^{18}$ we know that the cooperative monetary policymaker should pay attention not only to fluctuations in final-goods output gaps and final-goods PPI inflation rates, but also to fluctuations in intermediate-goods relative-price gaps and intermediate-goods PPI inflation rates.

Now we are prepared to characterize the optimal monetary policy for our two-country model with international trade in intermediate inputs. The policymaker chooses $\tilde{y}_{f t}, \tilde{y}_{f t}^{*}, \tilde{v}_{t}, v_{t}^{*}, \pi_{\mathrm{Hit}}, \pi_{\mathrm{Fit}}^{*}, \pi_{\mathrm{Hft}}$, and $\pi_{\mathrm{fft}}^{*}$ to minimize equation (46) subject to the sequence of equilibrium dynamics given by equations (36)-(41). During the analysis, we assume that the policymaker is able to commit, with full credibility, to the sequence of output gaps, relative-price gaps and inflation rates that solve the optimization problem. The first-order conditions are given by:

$$
\begin{aligned}
& 0=\frac{1}{2}\left[\frac{(1-\sigma)(v-1)^{2}}{(\sigma \Sigma)^{2}}-(1+\varphi)\left((2 \phi-1)+\frac{4 \phi(1-\phi)}{\Sigma}\right)^{2}\right]\left(\tilde{y}_{f t}^{*}-\tilde{y}_{f t}\right)+\frac{(\sigma+\varphi)}{2}\left(\tilde{y}_{f t}+\tilde{y}_{f t}^{*}\right) \\
& -2(1+\varphi) \phi(1-\phi)\left[(2 \phi-1)+\frac{4 \phi(1-\phi)}{\Sigma}\right]\left(\tilde{v}_{t}-\tilde{v}_{t}^{*}\right)+\frac{\delta_{f}(1-\phi)}{\Sigma}\left(\eta_{1 t}-\eta_{2 t}\right) \\
& -\frac{1}{2}\left[\frac{(1-\sigma)(v-1)^{2}}{(\sigma \Sigma)^{2}}-\frac{(1-2 \Lambda)(4 \phi(1-\phi)-\Sigma(1-2 \phi))}{\Sigma^{2}(1-2 \phi)}\right]\left(\bar{y}_{f t}-\bar{y}_{f t}^{*}\right) \\
& +\delta_{i}\left[\left((\sigma+\varphi \phi)+\frac{\Pi}{\Sigma}\right) \eta_{3 t}+\left(\varphi(1-\phi)-\frac{\Pi}{\Sigma}\right) \eta_{4 t}\right] \\
& 0=\frac{1}{2}\left[\frac{(1-\sigma)(v-1)^{2}}{(\sigma \Sigma)^{2}}-(1+\varphi)\left((2 \phi-1)+\frac{4 \phi(1-\phi)}{\Sigma}\right)^{2}\right]\left(\tilde{y}_{f t}-\tilde{y}_{f t}^{*}\right)+\frac{(\sigma+\varphi)}{2}\left(\tilde{y}_{f t}+\tilde{y}_{f t}^{*}\right) \\
& -2(1+\varphi) \phi(1-\phi)\left[(2 \phi-1)+\frac{4 \phi(1-\phi)}{\Sigma}\right]\left(\tilde{v}_{t}^{*}-\tilde{v}_{t}\right)+\frac{\delta_{f}(1-\phi)}{\Sigma}\left(\eta_{2 t}-\eta_{1 t}\right) \\
& -\frac{1}{2}\left[\frac{(1-\sigma)(v-1)^{2}}{(\sigma \Sigma)^{2}}-\frac{(1-2 \Lambda)(4 \phi(1-\phi)-\Sigma(1-2 \phi))}{\Sigma^{2}(1-2 \phi)}\right]\left(\bar{y}_{f t}^{*}-\bar{y}_{f t}\right) \\
& +\delta_{i}\left[\left((\sigma+\varphi \phi)+\frac{\Pi}{\Sigma}\right) \eta_{4 t}+\left(\varphi(1-\phi)-\frac{\Pi}{\Sigma}\right) \eta_{3 t}\right] \\
& 0=8(1+\varphi) \phi^{2}(1-\phi)^{2}\left(\tilde{v}_{t}-\tilde{v}_{t}^{*}\right)-2(1+\varphi) \phi(1-\phi)\left[(2 \phi-1)+\frac{4 \phi(1-\phi)}{\Sigma}\right]\left(\tilde{y}_{f t}-\tilde{y}_{f t}^{*}\right) \\
& -\frac{2 \phi(1-\phi)(1-2 \Lambda)}{\Sigma(1-2 \phi)}\left(\bar{y}_{f t}-\bar{y}_{f t}^{*}\right)+\delta_{f}\left[\phi \eta_{1 t}+(1-\phi) \eta_{2 t}\right]+\delta_{i}\left[2 \varphi \phi(1-\phi)\left(\eta_{4 t}-\eta_{3 t}\right)-\eta_{3 t}\right] \\
& +\eta_{5 t}-\beta \mathbf{E}_{t} \eta_{5 t+1} \\
& 0=8(1+\varphi) \phi^{2}(1-\phi)^{2}\left(\tilde{v}_{t}^{*}-\tilde{v}_{t}\right)-2(1+\varphi) \phi(1-\phi)\left[(2 \phi-1)+\frac{4 \phi(1-\phi)}{\Sigma}\right]\left(\tilde{y}_{f t}^{*}-\tilde{y}_{f t}\right) \\
& -\frac{2 \phi(1-\phi)(1-2 \Lambda)}{\Sigma(1-2 \phi)}\left(\bar{y}_{f t}^{*}-\bar{y}_{f t}\right)+\delta_{f}\left[\phi \eta_{1 t}+(1-\phi) \eta_{2 t}\right]+\delta_{i}\left[2 \varphi \phi(1-\phi)\left(\eta_{4 t}-\eta_{3 t}\right)-\eta_{3 t}\right] \\
& +\eta_{6 t}-\beta \mathbf{E}_{t} \eta_{6 t+1} \\
& 0=\frac{\xi_{f}}{\delta_{f}} \pi_{H f t}-\eta_{1 t}+\eta_{1 t-1}+\eta_{5 t} \\
& 0=\frac{\xi_{f}}{\delta_{f}} \pi_{f f t}^{*}-\eta_{2 t}+\eta_{2 t-1}+\eta_{6 t}
\end{aligned}
$$

\footnotetext{
18 When we disregard international trade in intermediate inputs, equation (46) is identical to its counterpart in Engel (2011) in the case of PCP.
} 


$$
\begin{aligned}
& 0=\frac{\xi_{i}}{\delta_{i}} \pi_{H i t}-\eta_{3 t}+\eta_{3 t-1}-\eta_{5 t} \\
& 0=\frac{\xi_{i}}{\delta_{i}} \pi_{F i t}^{*}-\eta_{4 t}+\eta_{4 t-1}-\eta_{6 t}
\end{aligned}
$$

in which $\eta_{1 t}, \eta_{2 t}, \eta_{3 t}, \eta_{4 t}, \eta_{5 t}$, and $\eta_{6 t}$ are the Lagrange multipliers associated with the constraints (36)-(41) respectively. Given initial values of $\tilde{v}_{-1}$ and $\tilde{v}_{-1}^{*}$, and $\eta_{1,-1}=\eta_{2,-1}=\eta_{3,-1}=\eta_{4,-1}=\eta_{5,-1}=\eta_{6,-1}=0$, equations (48)-(55) together with the constraints (36)-(41), constitute a dynamic system to describe the optimal monetary policy.

Having described the optimal monetary policy, we can compute its welfare loss according to the expected period welfare loss function (47). Then we use the welfare loss as a benchmark to assess various monetary policy rules, i.e. rank these rules on the basis of welfare losses. The one whose welfare loss is closest to that of the optimal monetary policy is considered to perform better than others.

\subsection{A numerical analysis of Taylor-type monetary policy rules}

In the following, three different Taylor-type monetary policy rules are considered. All of them require the nominal interest rate to respond systematically to final-goods output gap and some measures of inflation. In our model, it is natural to have three types of inflation as candidates: CPI inflation, finalgoods PPI inflation and intermediate-goods PPI inflation. Correspondingly, the first, which is called CPI-based Taylor rule (CPIT), has the nominal interest rate to target the CPI inflation. The second is referred to as the final-goods PPI-based Taylor rule (F-GPPIT), literally, final-goods PPI inflation is the target of the nominal interest rate. By the same logic, the last one has the nominal interest rate to respond to intermediate-goods PPI inflation and is named as the intermediate-goods PPI-based Taylor rule (I-GPPIT). To be specific, CPIT is specified as

$$
i_{t}=\rho+\phi_{\pi} \pi_{f t}+\phi_{y} \tilde{y}_{f t}, i_{t}^{*}=\rho+\phi_{\pi}^{*} \pi_{f t}^{*}+\phi_{y}^{*} \tilde{y}_{f t}^{*} .
$$

F-GPPIT is assumed to take the following form

$$
i_{t}=\rho+\phi_{\pi} \pi_{H f t}+\phi_{y} \tilde{y}_{f t}, i_{t}^{*}=\rho+\phi_{\pi}^{*} \pi_{f f t}^{*}+\phi_{y}^{*} \tilde{y}_{f t}^{*}
$$

Finally, I-GPPIT is described as

$$
i_{t}=\rho+\phi_{\pi} \pi_{H i t}+\phi_{y} \tilde{y}_{f t}, i_{t}^{*}=\rho+\phi_{\pi}^{*} \pi_{F i t}^{*}+\phi_{y}^{*} \tilde{y}_{f t}^{*}
$$

\subsubsection{Parameterization}

Before providing the results of the quantitative analysis under optimal monetary policy and various monetary policy rules, we introduce the baseline parameterization of the model. The parameter values used in the simulation are listed in Table 1. Following the literature, it is assumed that $\beta=0.99$, which implies that the annual real interest rate is $4 \%$ in the steady state and a period in the model corresponds to a quarter. The degree of risk aversion $\sigma$ takes a value of 2 which is in line with Corsetti et al. (2011). There is a wide discrepancy between micro and macro estimates of the Frisch elasticity of labor supply $\varphi^{-1}$. In the benchmark case, we set $\varphi$ to be 1 , which is relatively standard in macroeconomics and also adopted by Nakamura and Steinsson (2014). The parameter $v$, which represents the home bias in consumption, according to Engel (2011), is set to 1.5, implying a consumption share of 0.75 on domestic final goods. To describe the home bias in production, we follow Devereux and Engel (2007) and set $\phi$ to 0.5 , implying a share of 0.5 on domestic intermediate goods. The parameters $\xi_{f}$ and $\xi_{\text {i, }}$ which measure the elasticities of substitution between differentiated varieties at the two stages of 
Table 1

Parameter values in the benchmark case.

\begin{tabular}{lll}
\hline & Parameter & Value \\
\hline Discount factor & $\beta$ & 0.99 \\
Coefficient of relative risk aversion & $\sigma$ & 2 \\
Frisch elasticity of labor supply & $\varphi^{-1}$ & 1 \\
Home bias in consumption & $v$ & 1.5 \\
Home bias in production & $\phi$ & 0.5 \\
Elasticity of substitution between final goods & $\xi_{f}$ & 6 \\
Elasticity of substitution between intermediate goods & $\xi_{i}$ & 6 \\
Nominal contract duration in final-goods sector & $\theta_{f}$ & 0.75 \\
Nominal contract duration in intermediate-goods sector & $\theta_{i}$ & 0.75 \\
\hline
\end{tabular}

production, are both taken to be $6,{ }^{19}$ corresponding to a markup of $20 \%$ in the steady state. Regarding the frequency with which firms can adjust their prices, we consider $\theta_{f}=\theta_{i}=0.75$ as a benchmark case, ${ }^{20}$ which implies the average duration of the nominal contracts is four quarters. In view of the important role played by heterogeneity in price stickiness in New Keynesian models (Kara, 2015; Nakamura and Steinsson, 2010), when reporting the welfare losses, we also consider other 8 cases.

At time zero, the global economy is in its steady state. At time one, the economy is hit by unexpected world productivity shocks at both stages of production. As discussed above, our model features four productivity shocks and we assume that these shocks are uncorrelated across production stages and across countries. We set $\rho_{f}=\rho_{i}=\rho_{f}^{*}=\rho_{i}^{*}=0.95$ and $\operatorname{var}\left(\varepsilon_{f t}\right)=\operatorname{var}\left(\varepsilon_{i t}\right)=\operatorname{var}\left(\varepsilon_{f t}^{*}\right)=\operatorname{var}\left(\varepsilon_{i t}^{*}\right)=0.02^{2}$ to capture the persistence and variance of the shocks. Following Taylor (1993)'s initial calibration, we set $\phi_{\pi}=\phi_{\pi}^{*}=1.5, \phi_{y}=\phi_{y}^{*}=0.125 .^{21}$

\subsubsection{Impulse responses}

To begin with, we analyze the dynamic responses of some key macroeconomic variables to a home final-goods productivity shock. Fig. 1 displays the impulse responses under the above-mentioned four policy regimes.

Comparing with Clarida et al. (2002), Gali and Monacelli (2005), and Engel (2011) in which there is no production openness, we introduce a new channel into the model through which the exchange rate influences labor demands. Specifically, both the final-goods terms of trade and the intermediategoods terms of trade can affect the labor demands in both countries. In addition, different from the literature without vertical trade and production in which the home productivity shock only affects home labor demand. In our model, a productivity shock at the stage of final-goods production, whether in the home or foreign country, affects labor demands in both countries like a world shock.

When a positive productivity shock at the stage of home final-goods production occurs, home finalgoods producers' output increases and their marginal cost declines. Due to the model's structure, the positive productivity shock also drives home final-goods producers to lower the demands for both home and foreign intermediate goods. Thus, the shock acts as a negative demand shock for home and foreign intermediate-goods producers.

When monetary policy is chosen cooperatively under commitment, the nominal exchange rate is required to depreciate to shift world demands to home final goods. However, the depreciation inevitably shifts world demands for intermediate goods to the home country. The expenditure-switching effect implies an adverse demand shock to the foreign country. To counterbalance the shock, the policymaker lowers the foreign interest rate to boost aggregate consumption of foreign households.

\footnotetext{
19 The value of 6 is consistent with the literature. Among many others, a nonexhaustive list includes: Gali and Monacelli (2005, 2008) Gali (2008), Corsetti et al. (2011), Farhi and Werning (2012), Rabitsch (2012).

${ }^{20}$ See, among many others, Gali and Monacelli (2005, 2008), Huang and Liu (2005), Liu and Pappa (2008), Steinsson (2008) Engel (2011), Corsetti et al. (2011), Petrella and Santoro (2011), Petrella et al. (2013), Nakamura and Steinsson (2014).

${ }^{21}$ Note that $\rho=-\log \beta=0.0101$ is chosen to make the rules are consistent with a zero inflation steady state.
} 

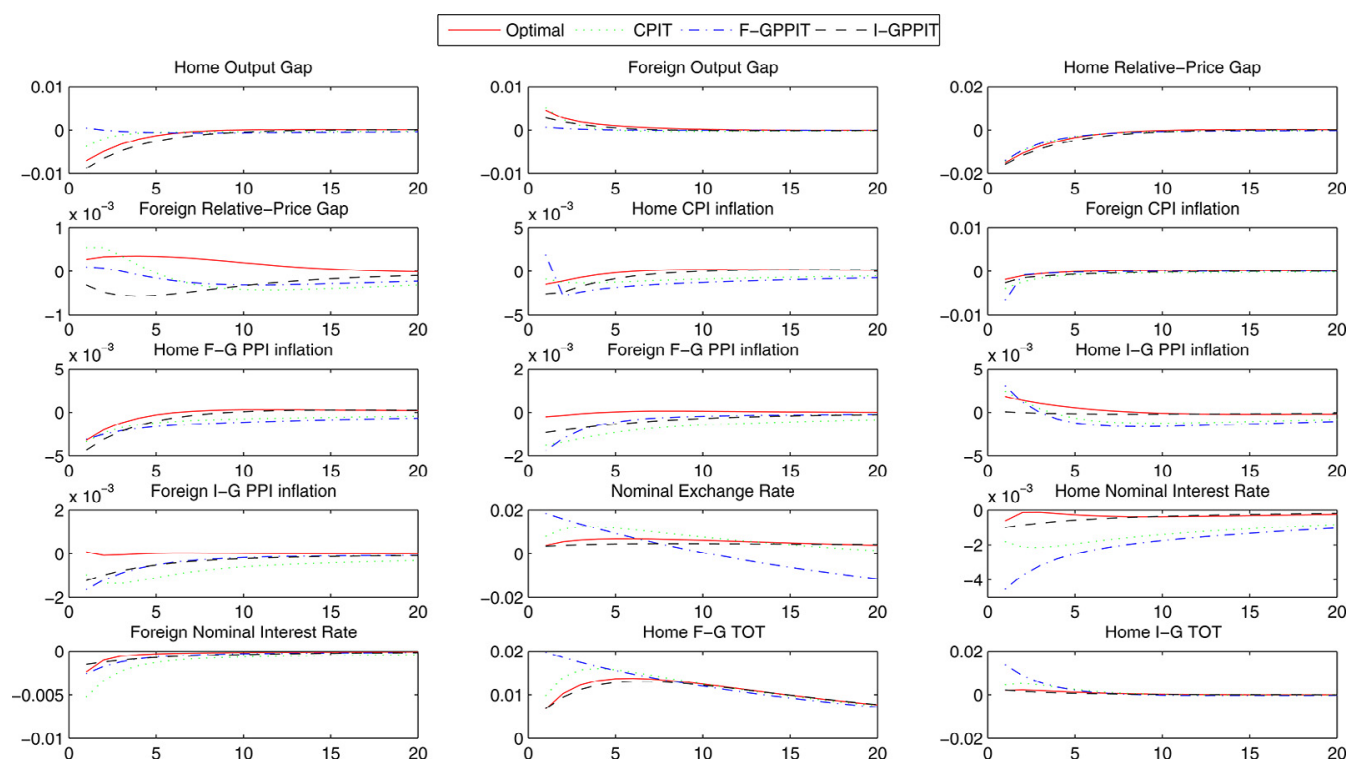

Fig. 1. Impulse responses to a home final-goods productivity shock under alternative policy regimes.

In the home country, the policymaker also needs to lower the interest rate to encourage home households to consume more to absorb the increased home final-goods output. Following the shock, the marginal cost facing home final-goods producers declines. These firms will lower their prices when it is their turn to set new prices. The downward adjustment of home final-goods prices and the depreciation of the exchange rate imply that the foreign country experiences CPI deflation. For the home country, although the depreciation of the exchange rate will push up the CPI inflation, the downward adjustment of home final-goods prices tends to lower the CPI inflation. In our calibrated model, the latter effect dominates the former, and the home country also experiences slight CPI deflation. At the current wage level, the decline in home consumption price level will increase real wage facing home workers, which implies that home workers are willing to supply more labor. However, the increase in consumption following the expansionary monetary policy decreases the utility revenue from offering an addition unit of labor, which means that home workers will supply less labor. In our calibrated model, the desire to supply less labor is greater than that to supply more. As for home labor demands, home intermediate-goods producers decrease the demand for home labor when home finalgoods producers reduce the input of home intermediate goods after the shock. However, the depreciation of the exchange rate encourages both home and foreign final-goods producers to substitute home intermediate goods for their foreign counterpart. In addition, the expansionary monetary policy in both countries will eventually increase the demands for home labor. But from equations (19), (20) and (21), we know that the decline in the demand for home labor caused by a positive productivity shock will exceed the increase from the expenditure-switching effect and the aggregate-demand effect. In our calibrated model, the decline in the supply of home labor exceeds that in the demand. As a result, home nominal wage goes up. When home intermediate-goods producers have the opportunity to adjust their prices, they will raise their prices, which results in positive home I-G PPI inflation. Foreign country's labor market can be analyzed similarly, except that the expenditure-switching effect will decrease the demand for foreign labor. Thus, foreign country's labor demand is lower than that in the home country and the decline in the demand for foreign labor is almost balanced by the decline in the supply. Thus foreign nominal wage and I-G PPI inflation almost keep unchanged. Facing rising input prices, a home final-goods producer has incentive to choose a higher price when its turn to choose price arrives. However, a positive productivity shock reduces its marginal cost so greatly that it lowers its price. Thus 
negative home F-G PPI inflation emerges. As regards a foreign final-goods producer, the depreciation of the exchange rate counteracts the increase in the prices of imported inputs, and the producer will adjust its chosen price downwards slightly. Thus slightly negative foreign F-G PPI inflation follows. By the same token, we can arrive at a conclusion that both countries will experience negative CPI inflation.

The positive productivity shock at the stage of home final-goods production has no influence on foreign relative price under the flexible prices equilibrium; however, it causes an equivalent increase in home efficient relative price. The above analysis implies a slightly positive foreign relative price gap and a negative home relative price gap. After the shock, home final-goods output increases more under the flexible prices equilibrium than under optimal monetary policy, thus a negative home finalgoods gap arises. As a comparison, foreign final-goods output under the flexible prices equilibrium declines, although optimal monetary policy delivers a slight rise in foreign final-goods output, the magnitude of the increase under optimal monetary policy falls short of the decrease under the flexible price equilibrium. Consequently, a positive foreign final-goods output gap appears. The depreciation of the exchange rate and price adjustments in both countries imply that the terms of trade of the home country deteriorates at both stages of production.

In our model, the presence of price stickiness at both stages of production makes both I-G PPI inflation and F-G PPI inflation play important roles in determining the joint welfare. To determine which Taylor-type monetary policy rule performs better, we need to see which one can do better than others to stabilize I-G PPI and F-G PPI inflation rates in both countries. In the benchmark case in which $\theta_{f}=\theta_{i}=0.75$, we can see from Fig. 1 that, by and large, I-GPPIT does a good job in keeping the inflation rates at both stages of production stable. Specifically, it performs best in stabilizing home and foreign I-G PPI inflation rates, and foreign F-G PPI inflation, but CPIT is slightly better than I-GPPIT in stabilizing home F-G PPI inflation. Does it mean that following I-GPPIT will bring minimal welfare loss to the monetary policymaker among three considered Taylor-type monetary policy rules? The answer is affirmative and we will show it in the next section.

It is noteworthy that F-GPPIT performs worst in stabilizing home I-G PPI inflation. As a result, although it performs better than CPIT in stabilizing foreign I-G PPI inflation, it is still the worst one to stabilize home and foreign I-G PPI inflation rates as a whole. Thus when stabilizing I-G PPI inflation rates in two countries becomes the policymaker's priority, this occurs when the price stickiness at the stage of intermediate-goods production causes great distortions, F-GPPIT can never be the policymaker's choice. As a comparison, I-GPPIT will be chosen to lower the joint welfare loss. As for stabilizing F-G PPI inflation, I-GPPIT performs best in stabilizing foreign F-G PPI inflation as mentioned above, whereas CPIT does better than the other two alternatives in stabilizing home F-G PPI inflation. Comparatively, F-GPPIT cannot produce desired stabilization of home and foreign F-G PPI inflation as a whole in the benchmark case.

A striking feature displayed in Fig. 1 is the ability of I-GPPIT to stabilize home I-G PPI inflation. Following I-GPPIT requires the nominal interest rate in the home country to respond slightly downwards, whereas its foreign counterpart to adjust at the same direction but with a more muted response. Uncovered interest parity implies a slight depreciation of the nominal exchange rate. The slightly expansionary monetary policy results in the most negative final-goods output gap in the home country. Thus, for one thing, a slightly expansionary monetary policy means that the aggregatedemand effect is weak and the households are not willing to reduce their labor supply greatly; and for another a slight depreciation of the nominal exchange rate implies that the expenditureswitching effect and the corresponding substitution effect of home for foreign intermediate goods are small and the demands for home labor are eventually determined by home final-goods producers. In our case, labor inputs decline after a positive productivity shock occurs. Consequently, comparing with the optimal monetary policy, following I-GPPIT will not cause a rising home wage, thus resulting in a positive I-G PPI inflation rate. As a matter of fact, it performs best in stabilizing home I-G PPI inflation.

Fig. 1 also shows that F-GPPIT performs worst in stabilizing home I-G PPI inflation. Why? Home final-goods producers need to adjust their prices to reflect the declining marginal cost after the shock occurs, thus, following F-GPPIT requires the nominal interest rate in the home country to respond greatly downward, whereas its foreign counterpart to adjust at the same direction but with a more slight response. Uncovered interest parity implies a huge depreciation of the nominal 
exchange rate. Contrary to the analysis in the above paragraph, the interaction of the aggregatedemand effect and expenditure-switching effect will push up the nominal wage greatly and cause a most positive I-G PPI inflation rate in the home country.

\subsubsection{Second moments and welfare losses}

In the literature on optimal monetary policy in open economies, it is widely believed that, in PCP case, central banks should target PPI inflation when the economy is buffeted by productivity shocks. The productivity shock and PPI inflation in the literature correspond to the productivity shock at the stage of final-goods production and F-G PPI inflation in our model respectively. In view of two natural candidates for PPI inflation being present in our model, targeting which PPI inflation needs to be distinguished. Furthermore, is it appropriate for the policymaker to always target PPI inflation when international trade in intermediate inputs is introduced and different degrees of price stickiness at the different stages of production are allowed?

Table 2 reports the welfare losses associated with optimal monetary policy under commitment and the three Taylor-type rules for various combinations of price stickiness at both stages of production. We consider 9 alternative cases, they are respectively: (1) $\theta_{i}=0.75$ and $\theta_{f}=0.75$, (2) $\theta_{i}=0.75$ and $\theta_{f}=0.5$, (3) $\theta_{i}=0.75$ and $\theta_{f}=0.25$, (4) $\theta_{i}=0.5$ and $\theta_{f}=0.75$, (5) $\theta_{i}=0.5$ and $\theta_{f}=0.5$, (6) $\theta_{i}=0.5$ and $\theta_{f}=0.25$, (7) $\theta_{i}=0.25$ and $\theta_{f}=0.75$, (8) $\theta_{i}=0.25$ and $\theta_{f}=0.5$, (9) $\theta_{i}=0.25$ and $\theta_{f}=0.25$.

Welfare losses comparison in Table 2 gives the policy rule that produces the highest level of welfare when the economy is buffeted by all shocks. It shows that the degree of price stickiness at the stage of intermediate-goods production is a key factor to determine which policy rule should be followed. Specifically, I-GPPIT results in the highest level of welfare when the degree of price stickiness at the stage of intermediate-goods production is high, whereas CPIT leads to the highest level of welfare when the degree of price stickiness at the stage of intermediate-goods production is intermediate or low.

What factors drive the ranking of the monetary policy rules illustrated in Table 2? Before answering the question, we must know the distortions in our model. Generally, the following distortions are present in our model: (1) monopolistic distortion, (2) price dispersion, (3) terms-of-trade distortion, (4) and relative-price distortion, among which the monopolistic distortion is eliminated by governments' subsidies raised in a lump-sum fashion. When implementing a cooperative monetary policy, the monetary policymaker is able to internalize the terms-of-trade externality, thus the price stickiness at both stages of production is the source of the remaining distortions. When implementing a cooperative monetary policy, the price stickiness at both stages of production is the source of the abovementioned distortions. After international trade in intermediate inputs is introduced, both home and foreign price dispersions at the stage of final-goods production will lead to an inefficient allocation of labor in any individual country. Thus, the welfare loss incurred from price dispersion at both stages of production should account for a substantial part of the aggregate welfare loss. To illustrate the point, we also report the values of the first term and the second term in equation (47) and their sum respectively in Table 3. The first term and the second term in equation (47) are defined respectively as $\mathbf{L}_{1} \equiv \frac{\xi_{i}}{2 \delta_{i}}\left(\operatorname{var}\left(\pi_{H i t}\right)+\operatorname{var}\left(\pi_{\mathrm{Fit}}^{*}\right)\right)$ and $\mathbf{L}_{2} \equiv \frac{\xi_{f}}{2 \delta_{f}}\left(\operatorname{var}\left(\pi_{\mathrm{Hft}}\right)+\operatorname{var}\left(\pi_{\mathrm{Ft} t}^{*}\right)\right)$. Note that in Tables 2 and 3, the welfare loss is computed as a percentage of steady state consumption (multiplied by 100).

Table 2

Welfare losses L when all shocks buffet the economy.

\begin{tabular}{lllll}
\hline & Optimal & CPIT & F-GPPIT & I-GPPIT \\
\hline $\mathbf{L}\left(\theta_{i}=0.75, \theta_{f}=0.75\right)$ & 0.2700 & 1.0800 & 1.2500 & 0.9700 \\
$\mathbf{L}\left(\theta_{i}=0.75, \theta_{f}=0.5\right)$ & 0.1700 & 0.8800 & 1.0600 & 0.6400 \\
$\mathbf{L}\left(\theta_{i}=0.75, \theta_{f}=0.25\right)$ & 0.0797 & 0.8300 & 1.0200 & 0.5300 \\
$\mathbf{L}\left(\theta_{i}=0.5, \theta_{f}=0.75\right)$ & 0.1400 & 0.6000 & 0.7200 & 0.7800 \\
$\mathbf{L}\left(\theta_{i}=0.5, \theta_{f}=0.5\right)$ & 0.1300 & 0.3500 & 0.4200 & 0.4500 \\
$\mathbf{L}\left(\theta_{i}=0.5, \theta_{f}=0.25\right)$ & 0.0733 & 0.2800 & 0.3500 & 0.3400 \\
$\mathbf{L}\left(\theta_{i}=0.25, \theta_{f}=0.75\right)$ & 0.0573 & 0.4400 & 0.5200 & 0.7400 \\
$\mathbf{L}\left(\theta_{i}=0.25, \theta_{f}=0.5\right)$ & 0.0665 & 0.1900 & 0.2100 & 0.4200 \\
$\mathbf{L}\left(\theta_{i}=0.25, \theta_{f}=0.25\right)$ & 0.0519 & 0.1300 & 0.1400 & 0.2800 \\
\hline
\end{tabular}


Table 3

Welfare losses caused by price stickiness when all shocks buffet the economy.

\begin{tabular}{lllll}
\hline & Optimal & CPIT & F-GPPIT & I-GPPIT \\
\hline $\mathbf{L}_{1}\left(\theta_{i}=0.75, \theta_{f}=0.75\right)$ & 0.0862 & 0.6200 & 0.7200 & 0.3300 \\
$\mathbf{L}_{2}\left(\theta_{i}=0.75, \theta_{f}=0.75\right)$ & 0.1800 & 0.4200 & 0.4700 & 0.6200 \\
$\mathbf{L}_{1}+\mathbf{L}_{2}\left(\theta_{i}=0.75, \theta_{f}=0.75\right)$ & 0.2662 & 1.0400 & 1.1900 & 0.9500 \\
$\mathbf{L}_{1}\left(\theta_{i}=0.75, \theta_{f}=0.5\right)$ & 0.0257 & 0.6700 & 0.8400 & 0.3300 \\
$\mathbf{L}_{2}\left(\theta_{i}=0.75, \theta_{f}=0.5\right)$ & 0.1400 & 0.1600 & 0.1500 & 0.2900 \\
$\mathbf{L}_{1}+\mathbf{L}_{2}\left(\theta_{i}=0.75, \theta_{f}=0.5\right)$ & 0.1657 & 0.8300 & 0.9900 & 0.6200 \\
$\mathbf{L}_{1}\left(\theta_{i}=0.75, \theta_{f}=0.25\right)$ & 0.0059 & 0.7200 & 0.9000 & 0.3400 \\
$\mathbf{L}_{2}\left(\theta_{i}=0.75, \theta_{f}=0.25\right)$ & 0.0711 & 0.0657 & 0.0531 & 0.1600 \\
$\mathbf{L}_{1}+\mathbf{L}_{2}\left(\theta_{i}=0.75, \theta_{f}=0.25\right)$ & 0.0770 & 0.7857 & 0.9531 & 0.5000 \\
$\mathbf{L}_{1}\left(\theta_{i}=0.5, \theta_{f}=0.75\right)$ & 0.0766 & 0.2200 & 0.2800 & 0.0706 \\
$\mathbf{L}_{2}\left(\theta_{i}=0.5, \theta_{f}=0.75\right)$ & 0.0588 & 0.3800 & 0.4300 & 0.7000 \\
$\mathbf{L}_{1}+\mathbf{L}_{2}\left(\theta_{i}=0.5, \theta_{f}=0.75\right)$ & 0.1354 & 0.6000 & 0.7100 & 0.7706 \\
$\mathbf{L}_{1}\left(\theta_{i}=0.5, \theta_{f}=0.5\right)$ & 0.0470 & 0.2200 & 0.3000 & 0.0899 \\
$\mathbf{L}_{2}\left(\theta_{i}=0.5, \theta_{f}=0.5\right)$ & 0.0794 & 0.1200 & 0.1100 & 0.3600 \\
$\mathbf{L}_{1}+\mathbf{L}_{2}\left(\theta_{i}=0.5, \theta_{f}=0.5\right)$ & 0.1264 & 0.3400 & 0.4100 & 0.4499 \\
$\mathbf{L}_{1}\left(\theta_{i}=0.5, \theta_{f}=0.25\right)$ & 0.0133 & 0.2200 & 0.3000 & 0.1400 \\
$\mathbf{L}_{2}\left(\theta_{i}=0.5, \theta_{f}=0.25\right)$ & 0.0594 & 0.0501 & 0.0358 & 0.1900 \\
$\mathbf{L}_{1}+\mathbf{L}_{2}\left(\theta_{i}=0.5, \theta_{f}=0.25\right)$ & 0.0727 & 0.2701 & 0.3358 & 0.3300 \\
$\mathbf{L}_{1}\left(\theta_{i}=0.25, \theta_{f}=0.75\right)$ & 0.0392 & 0.0803 & 0.1000 & 0.0166 \\
$\mathbf{L}_{2}\left(\theta_{i}=0.25, \theta_{f}=0.75\right)$ & 0.0173 & 0.3600 & 0.4100 & 0.7200 \\
$\mathbf{L}_{1}+\mathbf{L}_{2}\left(\theta_{i}=0.25, \theta_{f}=0.75\right)$ & 0.0565 & 0.4403 & 0.5100 & 0.7366 \\
$\mathbf{L}_{1}\left(\theta_{i}=0.25, \theta_{f}=0.5\right)$ & 0.0407 & 0.0835 & 0.1100 & 0.0245 \\
$\mathbf{L}_{2}\left(\theta_{i}=0.25, \theta_{f}=0.5\right)$ & 0.0257 & 0.1000 & 0.0899 & 0.3900 \\
$\mathbf{L}_{1}+\mathbf{L}_{2}\left(\theta_{i}=0.25, \theta_{f}=0.5\right)$ & 0.0664 & 0.1835 & 0.1999 & 0.4145 \\
$\mathbf{L}_{1}\left(\theta_{i}=0.25, \theta_{f}=0.25\right)$ & 0.0217 & 0.0837 & 0.1100 & 0.0578 \\
$\mathbf{L}_{2}\left(\theta_{i}=0.25, \theta_{f}=0.25\right)$ & 0.0302 & 0.0401 & 0.0235 & 0.2200 \\
$\mathbf{L}_{1}+\mathbf{L}_{2}\left(\theta_{i}=0.25, \theta_{f}=0.25\right)$ & 0.0519 & 0.1238 & 0.1335 & 0.2778 \\
\hline & & & &
\end{tabular}

A main finding in Table 3 is that welfare losses caused by price dispersion at both stages of production are nearly equal to aggregate welfare loss under optimal monetary policy and three Taylortype rules in our model. ${ }^{22}$ Thus the ranking of monetary policy rules, to a large degree, is determined by their abilities to stabilize I-G PPI and F-G PPI inflation rates. A careful inspection of Table 3 also reveals the following: (1) I-GPPIT outperforms both CPIT and F-GPPIT in stabilizing I-G PPI inflation rates; (2) I-GPPIT performs worst in stabilizing F-G PPI inflation rates; (3) F-GPPIT performs worst in stabilizing I-G PPI inflation rates. Thus, when the degree of price stickiness at the stage of intermediategoods production is high, the benefit from following I-GPPIT of reducing volatility of I-G PPI inflation rates significantly is greater than its cost caused by the most volatile F-G PPI inflation rates. Consequently, the policymaker should follow I-GPPIT, which can achieve the highest level of welfare. When the price stickiness at the stage of intermediate-goods production is intermediate or low, I-GPPIT and F-GPPIT are not chosen in our calibrated model for their respective weaknesses. Comparatively, CPIT can strike a balance in stabilizing I-G PPI and F-G PPI inflation rates and achieve the highest level of welfare.

As stated above, the price stickiness at both stages of production is the source of the distortions in our model. However, as shown in Tables 2 and 3, price dispersion at both stages of production is the most important factor to determine the aggregate welfare loss. Now we explain the point further. An efficient allocation requires that the representative household $h$ consumes the same amount of home final goods produced by different producers, i.e. for any $j_{f}, j_{f}^{\prime} \in[0,1], C_{H t}\left(h, j_{f}\right)=C_{H t}\left(h, j_{f}^{\prime}\right)$, in which $j_{f}, j_{f}^{\prime} \in[0,1]$ represent home different final-goods producers. For foreign final goods consumed by the representative household $h$, the same requirement also applies. Meanwhile, when an allocation is efficient, each home final-goods producer should input the same amount of home intermediate

\footnotetext{
22 We also calculate other terms in equation (47) under optimal monetary policy and other three Taylor-type monetary rules and find that each term and their sum are both small in quantity.
} 
goods produced by different producers, and the same is true for foreign intermediate goods, i.e. for any $j_{i}, j_{i}^{\prime} \in[0,1], j_{i}^{*}, j_{i}^{*^{\prime}} \in[0,1], Y_{\text {Hit }}\left(j_{f}, j_{i}\right)=Y_{\text {Hit }}\left(j_{f}, j_{i}^{\prime}\right), Y_{\text {Fit }}\left(j_{f}, j_{i}^{*}\right)=Y_{\text {Fit }}\left(j_{f}, j_{i}^{*^{\prime}}\right)$, in which $j_{i}, j_{i}^{\prime} \in[0,1]$ and $j_{i}^{*}, j_{i}^{*^{\prime}} \in[0,1]$ denote home and foreign different intermediate inputs respectively. Similarly, home different intermediate-goods producers use the same amount of labor, i.e. for any $j_{i}, j_{i}^{\prime} \in[0,1], N_{t}\left(j_{i}\right)=N_{t}\left(j_{i}^{\prime}\right)$. Evidently, the above requirements apply not only to home households and producers, but also to their foreign respective counterparts. However, when prices are sticky at both stages of production, the relative prices between different goods at the same stage and those between stages will change inefficiently and the same is true of the terms of trade at both stages of production. Consequently, an efficient allocation is unachievable.

In our model with vertical trade and production, we introduce a new channel through which openness influences labor markets. Specifically, the terms of trade at both stages of production can influence labor demands in a country. In addition, a productivity shock at the stage of final-goods production, whether in the home or foreign country, can affect labor demands in an individual country like a world shock. But when we consider global labor demands, the effects of the terms of trade due to relative prices between stages cancel out. Thus only price dispersion at both stages of production remains to influence global labor demands. ${ }^{23}$

The price stickiness at the stage of intermediate-goods production will induce labor to be devoted to producers with lower prices, which is an inefficient allocation of resources. When the degree of price stickiness at the stage of intermediate-goods production is high, the distortion at the stage is severe and the weight assigned to I-G PPI inflation rates becomes great. In this circumstance, by following I-GPPIT, which outperforms other alternatives in stabilizing I-G PPI inflation, the policymaker can reduce directly labor-demand dispersion among intermediate-goods producers and induce the allocation of labor to tend to be efficient. However, as shown in Table 3, the efficiency improving comes with a cost. Specifically, among three Taylor-type monetary policy rules, I-GPPIT performs worst in stabilizing F-G PPI inflation. And great volatility of F-G PPI inflation rates will deteriorate the allocation of consumption, and eventually, due to international trade in intermediate inputs, the allocation of global labor. Thus, when the degree of the price stickiness at the stage of intermediate-goods production is intermediate or low, the direct benefit of I-GPPIT from an efficient allocation of global labor would be dominated by the indirect cost from an inefficient allocation of global consumption, the policymaker should not follow I-GPPIT. Table 3 also records that F-GPPIT performs worst in stabilizing I-G PPI inflation rates, meanwhile, its ability to stabilize F-G PPI inflation rates is overtook by CPIT in our calibrated model when the degree of price stickiness at the stage of final-goods production is high. As a comparison CPIT can strike a balance in stabilizing I-G PPI and F-G PPI inflation rates and achieve the highest level of welfare. Therefore, by and large, when the degree of price stickiness at the stage of intermediate-goods production is intermediate or low, the policymaker should follow CPIT.

In the literature, the stabilization of PPI inflation rates can induce an efficient allocation of consumption and labor simultaneously in PCP case, thus the policymaker should target PPI inflation. In our model, although the stabilization of F-G PPI inflation rates can induce an efficient allocation of consumption as before, it is the stabilization of I-G PPI inflation rates that is required to induce an efficient allocation of labor.

\subsubsection{Sensitivity analysis}

When all shocks buffet the economy, does our conclusion hold for other crucial parameters? We now conduct sensitivity analysis with respect to four important parameters, which affect the weights

\footnotetext{
23 Using equations (32), (33), (34), (35) and log-linearized version of equation (21), we have $n_{t}=[\phi+$ $\left.\frac{2 \sigma \phi(1-\phi)}{(v-1)^{2}+2 \sigma v\left(1-\frac{v}{2}\right)}\right] y_{f t}+\left[(1-\phi)-\frac{2 \sigma \phi(1-\phi)}{(v-1)^{2}+2 \sigma v\left(1-\frac{v}{2}\right)}\right] y_{f t}^{*}+2 \phi(1-\phi) v_{t}^{*}-2 \phi(1-\phi) v_{t}+d_{i t}+\phi d_{f t}+(1-\phi) d_{f t}^{*}-a_{i t}-\phi a_{f t}-(1-\phi) a_{f t}^{*}$. Similarly, we have $n_{t}^{*}=\left[\phi+\frac{2 \sigma \phi(1-\phi)}{(v-1)^{2}+2 \sigma v\left(1-\frac{v}{2}\right)}\right] y_{f t}^{*}+\left[(1-\phi)-\frac{2 \sigma \phi(1-\phi)}{(v-1)^{2}+2 \sigma v\left(1-\frac{v}{2}\right)}\right] y_{f t}+2 \phi(1-\phi) v_{t}-2 \phi(1-\phi) v_{t}^{*}+d_{i t}^{*}+\phi d_{f t}^{*}+$ $(1-\phi) d_{f t}-a_{i t}^{*}-\phi a_{f t}^{*}-(1-\phi) a_{f t}$. Thus, $n_{t}+n_{t}^{*}=y_{f t}+y_{f t}^{*}+d_{i t}+d_{i t}^{*}+d_{f t}+d_{f t}^{*}-a_{i t}-a_{i t}^{*}-a_{f t}-a_{f t}^{*}$.
} 
Table 4

Welfare losses L when the Frisch elasticity of labor supply is $3 / 4$.

\begin{tabular}{lllll}
\hline & Optimal & CPIT & F-GPPIT & I-GPPIT \\
\hline $\mathbf{L}\left(\theta_{i}=0.75, \theta_{f}=0.75\right)$ & 0.2700 & 1.1800 & 1.3800 & 1.0600 \\
$\mathbf{L}\left(\theta_{i}=0.75, \theta_{f}=0.5\right)$ & 0.1700 & 0.9600 & 1.1500 & 0.6900 \\
$\mathbf{L}\left(\theta_{i}=0.75, \theta_{f}=0.25\right)$ & 0.0810 & 0.9000 & 1.1200 & 0.5700 \\
$\mathbf{L}\left(\theta_{i}=0.5, \theta_{f}=0.75\right)$ & 0.1400 & 0.6600 & 0.7800 & 0.8500 \\
$\mathbf{L}\left(\theta_{i}=0.5, \theta_{f}=0.5\right)$ & 0.1300 & 0.3800 & 0.4500 & 0.4800 \\
$\mathbf{L}\left(\theta_{i}=0.5, \theta_{f}=0.25\right)$ & 0.0741 & 0.3000 & 0.3800 & 0.3700 \\
$\mathbf{L}\left(\theta_{i}=0.25, \theta_{f}=0.75\right)$ & 0.0575 & 0.4800 & 0.5600 & 0.8100 \\
$\mathbf{L}\left(\theta_{i}=0.25, \theta_{f}=0.5\right)$ & 0.0667 & 0.2000 & 0.2200 & 0.4400 \\
$\mathbf{L}\left(\theta_{i}=0.25, \theta_{f}=0.25\right)$ & 0.0523 & 0.1300 & 0.1500 & 0.2900 \\
\hline
\end{tabular}

Table 5

Welfare losses L when the coefficient of relative risk aversion is 5 .

\begin{tabular}{lllll}
\hline & Optimal & CPIT & F-GPPIT & I-GPPIT \\
\hline $\mathbf{L}\left(\theta_{i}=0.75, \theta_{f}=0.75\right)$ & 0.2600 & 1.4500 & 1.6200 & 1.2500 \\
$\mathbf{L}\left(\theta_{i}=0.75, \theta_{f}=0.5\right)$ & 0.1700 & 1.1300 & 1.3100 & 0.8000 \\
$\mathbf{L}\left(\theta_{i}=0.75, \theta_{f}=0.25\right)$ & 0.0799 & 1.0600 & 1.2600 & 0.6600 \\
$\mathbf{L}\left(\theta_{i}=0.5, \theta_{f}=0.75\right)$ & 0.1400 & 0.8300 & 0.9500 & 0.9700 \\
$\mathbf{L}\left(\theta_{i}=0.5, \theta_{f}=0.5\right)$ & 0.1300 & 0.4300 & 0.5000 & 0.5000 \\
$\mathbf{L}\left(\theta_{i}=0.5, \theta_{f}=0.25\right)$ & 0.0734 & 0.3200 & 0.4000 & 0.3600 \\
$\mathbf{L}\left(\theta_{i}=0.25, \theta_{f}=0.75\right)$ & 0.0568 & 0.6500 & 0.7200 & 0.9100 \\
$\mathbf{L}\left(\theta_{i}=0.25, \theta_{f}=0.5\right)$ & 0.0665 & 0.2300 & 0.2500 & 0.4500 \\
$\mathbf{L}\left(\theta_{i}=0.25, \theta_{f}=0.25\right)$ & 0.0520 & 0.1400 & 0.1600 & 0.2800 \\
\hline
\end{tabular}

of the various variables in the welfare loss function. They are respectively: (1) Frisch elasticity of labor supply, (2) coefficient of relative risk aversion, (3) home bias in consumption, (4) and home bias in production. The results will be reported in Tables 4-7 in turn.

As mentioned above, there is a wide range of estimates of the Frisch elasticity of labor supply in micro and macro literature. Using the evidence on the intensive and extensive margins, Chetty et al. (2011) review the topic and conclude that the Frisch elasticity of labor supply being 0.75 is a reasonable value to simulate a representative agent macro model. Table 4 reports the welfare losses associated with optimal monetary policy under commitment and three Taylor-type rules when the Frisch elasticity of labor supply is 0.75 . The decline in Frisch elasticity of labor supply implies the increase of disutility of offering an additional unit of labor, thus increasing the volatility of hours at equilibrium. As a result, the volatility of wages and inflation rates at both stages of the production will rise, so do the welfare losses. But the previous analysis still holds. Another important parameter in equation (47) is the coefficient of relative risk aversion. Table 5 reports the welfare losses when $\sigma=5$, which is also used by Chari et al. (2002) and Farhi et al. (2014); a higher $\sigma$ will lower the utility revenue of offering an additional unit of labor, thus decreasing households' willingness to supply labor, which increases the volatility of hours at equilibrium. Like the case in which Frisch elasticity of labor supply declines, the welfare losses will rise, but our findings remain unchanged.

We also experiment with a $10 \%$ increase in home bias in consumption. Table 6 reports the welfare losses when $v=1.65$, which corresponds to a home bias in consumption of 0.825 . Finally, Table 7 reports the welfare losses associated with a 20\% increase in home bias in production. The findings in Tables 6 and 7 also confirm our previous conclusion.

\section{Conclusion}

In this paper we introduce international trade in intermediate inputs into an otherwise standard two-country New Keynesian model to study optimal monetary policy. In the literature without vertical trade and production, a productivity shock in a country will only influence its domestic labor 
Table 6

Welfare losses $\mathrm{L}$ when the home bias in consumption is 0.825 .

\begin{tabular}{lllll}
\hline & Optimal & CPIT & F-GPPIT & I-GPPIT \\
\hline $\mathbf{L}\left(\theta_{i}=0.75, \theta_{f}=0.75\right)$ & 0.2700 & 1.1200 & 1.2600 & 0.9700 \\
$\mathbf{L}\left(\theta_{i}=0.75, \theta_{f}=0.5\right)$ & 0.1700 & 0.9200 & 1.0600 & 0.6400 \\
$\mathbf{L}\left(\theta_{i}=0.75, \theta_{f}=0.25\right)$ & 0.0794 & 0.8600 & 1.0300 & 0.5300 \\
$\mathbf{L}\left(\theta_{i}=0.5, \theta_{f}=0.75\right)$ & 0.1400 & 0.6200 & 0.7200 & 0.7800 \\
$\mathbf{L}\left(\theta_{i}=0.5, \theta_{f}=0.5\right)$ & 0.1300 & 0.3600 & 0.4200 & 0.4600 \\
$\mathbf{L}\left(\theta_{i}=0.5, \theta_{f}=0.25\right)$ & 0.0730 & 0.2900 & 0.3600 & 0.3400 \\
$\mathbf{L}\left(\theta_{i}=0.25, \theta_{f}=0.75\right)$ & 0.0567 & 0.4500 & 0.5200 & 0.7500 \\
$\mathbf{L}\left(\theta_{i}=0.25, \theta_{f}=0.5\right)$ & 0.0661 & 0.1800 & 0.2100 & 0.4200 \\
$\mathbf{L}\left(\theta_{i}=0.25, \theta_{f}=0.25\right)$ & 0.0517 & 0.1200 & 0.1400 & 0.2800 \\
\hline
\end{tabular}

Table 7

Welfare losses $\mathrm{L}$ when the home bias in production is 0.6.

\begin{tabular}{lllll}
\hline & Optimal & CPIT & F-GPPIT & I-GPPIT \\
\hline $\mathbf{L}\left(\theta_{i}=0.75, \theta_{f}=0.75\right)$ & 0.2300 & 1.0100 & 1.1600 & 0.9200 \\
$\mathbf{L}\left(\theta_{i}=0.75, \theta_{f}=0.5\right)$ & 0.1500 & 0.8100 & 0.9400 & 0.6100 \\
$\mathbf{L}\left(\theta_{i}=0.75, \theta_{f}=0.25\right)$ & 0.0713 & 0.7600 & 0.8900 & 0.4900 \\
$\mathbf{L}\left(\theta_{i}=0.5, \theta_{f}=0.75\right)$ & 0.1200 & 0.5800 & 0.6800 & 0.7500 \\
$\mathbf{L}\left(\theta_{i}=0.5, \theta_{f}=0.5\right)$ & 0.1100 & 0.3300 & 0.3800 & 0.4300 \\
$\mathbf{L}\left(\theta_{i}=0.5, \theta_{f}=0.25\right)$ & 0.0649 & 0.2600 & 0.3100 & 0.3100 \\
$\mathbf{L}\left(\theta_{i}=0.25, \theta_{f}=0.75\right)$ & 0.0501 & 0.4400 & 0.5000 & 0.7200 \\
$\mathbf{L}\left(\theta_{i}=0.25, \theta_{f}=0.5\right)$ & 0.0581 & 0.1800 & 0.1900 & 0.3900 \\
$\mathbf{L}\left(\theta_{i}=0.25, \theta_{f}=0.25\right)$ & 0.0457 & 0.1200 & 0.1300 & 0.2500 \\
\hline
\end{tabular}

demand. In our model with two stages of production and international trade in intermediate inputs, a productivity shock at the stage of final-goods production in either country affects both countries like a world shock. In addition to final-goods terms of trade, intermediate-goods terms of trade also affects labor demands in both countries. As evidenced in the empirical literature, we assume different degrees of price stickiness at different stages of production.

When we consider international trade in intermediate inputs, a cooperative monetary policymaker should pay attention not only to fluctuations in final-goods output gaps and final-goods PPI inflation rates, but also to fluctuations in intermediate-goods relative-price gaps and intermediate-goods PPI inflation rates. In addition, we show that the efficient allocation cannot be achieved in any case. To derive the second-best monetary policy, we do a second-order approximation to the joint welfare function of the home and foreign households; the policymaker commits to his policy rule and maximizes the joint welfare function. Then we use the second-best welfare level as a benchmark to evaluate three alternative Taylor-type monetary rules: (1) a CPI-based Taylor rule (CPIT), (2) a final-goods PPI-based Taylor rule (F-GPPIT), and (3) an intermediate-goods PPI-based Taylor rule (I-GPPIT).

When the economy is buffeted by global productivity shocks at both stages, we find that the degree of price stickiness at the stage of intermediate-goods production is a key factor to determine which policy rule should be followed. Specifically, when the degree of price stickiness at the stage of intermediate-goods production is high, the policymaker should follow I-GPPIT, whereas CPIT leads to the highest level of welfare and should be followed when the degree of price stickiness at the stage of intermediate-goods production is intermediate or low.

In our model, we assume sticky prices but flexible wages. However, large empirical evidence shows that wages are sticky. In addition, wage stickiness is shown to be more important than price stickiness in the analysis of business cycle fluctuations (Chari et al., 2000; Huang and Liu, 2002). It is certain that incorporating both price and wage stickiness has important implications for the design of optimal monetary policy (Erceg et al., 2000; Rhee and Turdaliev, 2013). When there is trade in intermediate inputs, both the final-goods terms of trade and the intermediate-goods terms of trade can affect the labor demands in both countries. Furthermore, a productivity shock at the stage of final- 
goods production, whether in the home or foreign country, affects labor demands in both countries like a world shock. It implies that wage stickiness would provide an additional effect of production openness on labor markets. Thus an interesting extension of the present paper could incorporate both price and wage stickiness and see how the design of optimal monetary policy is influenced. We leave the point as an avenue for further research.

\section{Acknowledgments}

We appreciate comments from Charles Engel, Giancarlo Corsetti, Kevin X.D. Huang, Luisa Lambertini, Jiandong Ju, Xiaoyong Cui, and seminar participants of Macro Group at GSM. We are indebted very much to the editor, Joshua Aizenman, and two anonymous referees for the insightful comments and suggestions. The corresponding author acknowledges financial support from China Postdoctoral Science Foundation, Grant Number 2014M560832. He is also grateful to Hongkui Liu, Chen Guo, Feng Shi, Wei $\mathrm{Tu}$, and Xin Chen for their help.

\section{Appendix. Supplementary material}

Supplementary data to this article can be found online at doi:10.1016/j.jimonfin.2016.03.007.

\section{References}

Atkeson, A., Burstein, A., 2008. Pricing to market, trade costs, and international relative price. Am. Econ. Rev. 98:5, $1998-2031$. Benigno, G., Benigno, P., 2003. Price stability in open economies. Rev. Econ. Stud. 70, 743-764.

Benigno, G., Benigno, P., 2006. Designing targeting rules for international monetary policy cooperation. J. Monet. Econ. 53, 473-506. Benigno, P., 2004. Optimal monetary policy in a currency area. J. Int. Econ. 63, 293-320.

Benigno, P., 2009. Price stability with imperfect financial integration. J. Money Credit Bank. 41, 121-149.

Betts, C., Devereux, M.B., 2000. Exchange rate dynamics in a model of pricing-to-market. J. Int. Econ. 50, 215-244.

Bils, M., Klenow, P.J., 2004. Some evidence on the importance of sticky prices. J. Polit. Econ. 112, 947-985.

Blanchard, O., Gali, J., 2007. Real wage rigidities and the New Keynesian model. J. Money Credit Bank. 39, 35-65.

Bridgman, B., 2012. The rise of vertical specialization trade. J. Int. Econ. 86, 133-140.

Calvo, G., 1983. Staggered prices in a utility maximizing framework. J. Monet. Econ. 12, 383-398.

Canzoneri, M.B., Cumby, R.E., Diba, B.T., 2005. The need for international policy coordination: what's old, what's new, what's yet to come? J. Int. Econ. 66, 363-384.

Chari, V.V., Kehoe, P., MaGrattan, E., 2000. Sticky price models of the business cycle: can the contract multiplier solve the persistence problem? Econometrica 68, 1151-1179.

Chari, V.V., Kehoe, P., MaGrattan, E., 2002. Can sticky price models generate volatile and persistent real exchange rates? Rev. Econ. Stud. 69, 533-563.

Chetty, R., Guren, A., Manoli, D., Weber, A., 2011. Are micro and macro labor supply elasticities consistent? A review of evidence on the intensive and extensive margins. Am. Econ. Rev. 101 (3), 471-475.

Clarida, R., Gali, J., Gertler, M., 2001. Optimal monetary policy in open versus closed economies: an integrated approach. Am. Econ. Rev. 91, 248-252.

Clarida, R., Gali, J., Gertler, M., 2002. A simple framework for international monetary policy analysis. J. Monet. Econ. 49, 879-904.

Clark, T.E., 1999. The responses of prices at different stages of production to monetary policy shocks. Rev. Econ. Stat. 81, 420-433.

Corsetti, G., Pesenti, P., 2005. International dimensions of optimal monetary policy. J. Monet. Econ. 52, 281-305.

Corsetti, G., Dedola, L., Leduc, S., 2011. Optimal monetary policy in open economies. In: Friedman, B.M., Woodford, M. (Eds.), Handbook of Monetary Economics, vol. 3. Elsevier, Philadelphia, PA, pp. 861-934.

Devereux, M.B., Engel, C., 2003. Monetary policy in the open economy revisited: price setting and exchange rate flexibility. Rev. Econ. Stud. 70, 765-783.

Devereux, M.B., Engel, C., 2007. Expending switching versus real exchange rate stabilization: competing objectives for exchange rate policy. J. Monet. Econ. 54, 2346-2374.

Devereux, M.B., Sutherland, A., 2008. Financial globalization and monetary policy. J. Monet. Econ. 55, 1363-1375.

Devereux, M.B., Lane, P.R., Juanyi, X., 2006. Exchange rate and monetary policy in emerging market economies. Econ. J. 116, 478-506.

Devereux, M.B., Kang, S., Juanyi, X., 2007. Global monetary policy under a dollar standard. J. Int. Econ. 71, 113-132.

Duarte, M., Obstfeld, M., 2008. Monetary policy in the open economy revisited: the case for exchange-rate flexibility restored. J. Int. Money. Finance 27, 949-957.

Engel, C., 1999. Accounting for U.S. real exchange rate changes. J. Polit. Econ. 107 (3), 507-538.

Engel, C., 2011. Currency misalignments and optimal monetary policy: a reexamination. Am. Econ. Rev. 101, $2796-2822$.

Erceg, C., Henderson, D.W., Levin, A.T., 2000. Optimal monetary policy with staggered wage and price contracts. J. Monet. Econ. 46, 281-313.

Farhi, E., Werning, I., 2012. Dealing with the trilemma: optimal capital controls with fixed exchange rates. Working Paper.

Farhi, E., Gopinath, G., Itskhoki, O., 2014. Fiscal devaluations. Rev. Econ. Stud. 81, 725-760.

Feenstra, R.C., 1998. Integration of trade and disintegration of production in the global economy. J. Econ. Perspect. 12, 31-50.

Feenstra, R.C., Luck, P., Obstfeld, M., Russ, K.N., 2014. In search of the Armington elasticity. NBER Working Paper No. 20063. 
Gali, J., 2008. Monetary Policy, Inflation, and the Business Cycle: An Introduction to the New Keynesian Framework. Princeton University Press, Princeton.

Gali, J., Monacelli, T., 2005. Monetary policy and exchange rate volatility in a small open economy. Rev. Econ. Stud. 72, 707-734.

Gali, J., Monacelli, T., 2008. Optimal monetary and fiscal policy in a currency union. J. Int. Econ. 76, 116-132.

Huang, K.X.D., Liu, Z., 2001. Production chains and general equilibrium aggregate dynamics. J. Monet. Econ. 48, 437-462.

Huang, K.X.D., Liu, Z., 2002. Staggered price-setting, staggered wage-setting and business cycle persistence. J. Monet. Econ. 49, 405-433.

Huang, K.X.D., Liu, Z., 2005. Inflation targeting: what inflation rate to target? J. Monet. Econ. 52, 1435-1462.

Huang, K.X.D., Liu, Z., 2006. Seller's local currency pricing or buyers' local currency pricing: Does it matter for international welfare analysis? J. Econ. Dyn. Control 30, 1183-1213.

Huang, K.X.D., Liu, Z., 2007. Business cycles with staggered prices and international trade in intermediate inputs. J. Monet. Econ. $54,1271-1289$.

Hummels, D., Dana, R., Yi, K.-M., 1998. Vertical specialization and the changing nature of world trade. Econ. Policy Rev. 4, 79-99.

Hummels, D., Jun, I., Yi, K.-M., 2001. The nature and growth of vertical specialization in world trade. J. Int. Econ. 54, 75-96.

Johnson, R.C., 2014. Trade in intermediate inputs and business cycle comovement. Am. Econ. J. Macroecon. 6 (4), 39-83.

Justiniano, A., Primiceri, G.E., Tambalotti, A., 2013. Is there a trade-off between inflation and output stabilization. Am. Econ. J. Macroecon. 5 (2), 1-31.

Kara, E., 2015. The reset inflation puzzle and the heterogeneity in price stickiness. J. Monet. Econ. 76, 29-37.

Liu, Z., Pappa, E., 2008. Gains from international monetary policy coordination: Does it pay to be different? J. Econ. Dyn. Control $32,2085-2117$.

Monacelli, T., 2013. Is monetary policy in an open economy fundamentally different? IMF Econ. Rev. 61, 6-21.

Murphy, K.M., Shleifer, A., Vishny, R.W., 1989. Building blocks of market clearing business cycle models. NBER Macroecon. Annu. 4, 247-287.

Nakamura, E., Steinsson, J., 2008. Five facts about prices: a reevaluation of menu cost models. Q. J. Econ. 123, 1415-1464.

Nakamura, E., Steinsson, J., 2010. Monetary non-neutrality in a multisector menu cost model. Q. J. Econ. 125 (3), $961-1013$.

Nakamura, E., Steinsson, J., 2014. Fiscal stimulus in a monetary union: evidence from U.S. regions. Am. Econ. Rev. 104(3), 753-792.

Obstfeld, M., 2001. International macroeconomics: beyond the Mundell-Fleming model. IMF Staff Pap. 47 (Special Issue), 1-39.

Obstfeld, M., Rogoff, K., 2000. New directions for stochastic open economy models. J. Int. Econ. 50, 117-153.

Obstfeld, M., Rogoff, K., 2002. Global implications of self-oriented national monetary rules. Q. J. Econ. 117, 503-535.

Paoli, B.D., 2009a. Monetary policy and welfare in a small open economy. J. Int. Econ. 77, 11-22.

Paoli, B.D., 2009b. Monetary policy under alternative asset market structures: the case of a small open economy. J. Money Credit Bank. 41, 1301-1330.

Pappa, E., 2004. Do the ECB and the fed really need to cooperate? optimal monetary policy in a two-country world. J. Monet. Econ. 51, 753-779.

Petrella, I., Santoro, E., 2011. Input-output interactions and optimal monetary policy. J. Econ. Dyn. Control 35, 1817-1830.

Petrella, I., Rossi, R., Santoro, E., 2013. Monetary policy with sectoral trade-offs. Working paper.

Rabitsch, K., 2012. The role of financial market structure and the trade elasticity for monetary policy in open economies. J. Money Credit Bank. 44, 603-629.

Rhee, H.J., Turdaliev, N., 2013. Optimal monetary policy in a small open economy with staggered wage and price contracts. J. Int. Money. Finance 37, 306-323.

Shi, K., Xu, J.Y., 2007. Optimal monetary policy with vertical production and trade. Rev. Int. Econ. 15 (3), 514-537.

Steinsson, J., 2008. The dynamic behavior of the real exchange rate in sticky price models. Am. Econ. Rev. 98(1), 519-533.

Sutherland, A., 2006. The expenditure-switching effect, welfare and monetary policy in a small open economy. J. Econ. Dyn. Control 30, 1159-1182.

Taylor, J.B., 1993. Discretion versus policy rules in practice. J. Monet. Econ. 39, 159-214.

Teo, W., 2011. Inventories and optimal monetary policy in a small open economy. J. Int. Money. Finance 30, 1719-1748.

Wang, C., Zou, H.F., 2013. On the efficiency of monetary and fiscal policy in open economies. Ann. Econ. Finance 14, 179-206.

Wang, C., Zou, H.F., 2015. Optimal monetary policy under a global dollar standard: the effect of vertical trade and production. Open Economies Rev. 126, 121-137.

Woodford, M., 2003. Interest and Prices: Foundations of a Theory of Monetary Policy. Princeton University Press, Princeton.

Yi, K.-M., 2003. Can vertical specialization explain the growth of world trade? J. Polit. Econ. 111, 52-102.

Yi, K.-M., 2010. Can multistage production explain the home bias in trade? Am. Econ. Rev. 100(1), 364-393. 